\title{
Aberrant Mucin Assembly in Mice Causes Endoplasmic Reticulum Stress and Spontaneous Inflammation Resembling Ulcerative Colitis
}

\author{
Chad K. Heazlewood ${ }^{1 \odot}$, Matthew C. Cook $^{2 \odot x}$, Rajaraman Eri ${ }^{1 \odot}$, Gareth R. Price ${ }^{3}$, Sharyn B. Tauro ${ }^{1}$, Douglas Taupin ${ }^{4}$, \\ David J. Thornton ${ }^{5}$, Chin Wen Png ${ }^{1}$, Tanya L. Crockford ${ }^{6}$, Richard J. Cornall ${ }^{6}$, Rachel Adams ${ }^{1}$, Masato Kato ${ }^{7}$, \\ Keats A. Nelms ${ }^{2 \alpha}$, Nancy A. Hong ${ }^{8}$, Timothy H. J. Florin ${ }^{1}$, Christopher C. Goodnow ${ }^{9}$, Michael A. McGuckin ${ }^{1{ }^{*}}$ \\ 1 Mucin and IBD Research Teams, Mucosal Diseases Program, Mater Medical Research Institute, and the University of Queensland, Aubigny Place, Mater Health Services, \\ South Brisbane, Queensland, Australia, 2 Immunology and Inflammation Group, Phenomix Australia, Acton, Australia, 3 Molecular Genetics Team, Mater Medical Research \\ Institute, and the University of Queensland, Aubigny Place, Mater Health Services, South Brisbane, Queensland, Australia, 4 Gastroenterology Unit, Canberra Hospital, Woden, \\ Australia, 5 Wellcome Trust Centre for Cell Matrix Research, Faculty of Life Sciences, University of Manchester, Manchester, United Kingdom, 6 Nuffield Dept of Clinical \\ Medicine, University of Oxford, John Radcliffe Hospital, Oxford, United Kingdom, 7 Dendritic Cell Program, Mater Medical Research Institute, Aubigny Place, Mater Health \\ Services, South Brisbane, Queensland, Australia, 8 Phenomix Corporation, San Diego, California, United States of America, 9 Division of Immunology and Genetics and \\ Australian Phenomics Facility, John Curtin School of Medical Research, The Australian National University, Canberra, Australia
}

Funding: See section at end of manuscript.

Competing Interests: The authors have declared that no competing interests exist.

Academic Editor: Stefan Schreiber, University Hospital Schleswig

Holstein, Germany

Citation: Heazlewood CK, Cook MC, Eri R, Price GR, Tauro SB, et al. (2008) Aberrant mucin assembly in mice causes endoplasmic reticulum stress and spontaneous inflammation resembling ulcerative colitis. PLoS Med 5(3): e54. doi:10.1371/journal. pmed.0050054

Received: May 14, 2007

Accepted: January 17, 2008

Published: March 4, 2008

Copyright: (c) 2008 Heazlewood et al. This is an open-access article distributed under the terms of the Creative Commons Attribution License, which permits unrestricted use, distribution, and reproduction in any medium, provided the original author and source are credited.

Abbreviations: DBA, Dolichos biflorus agglutinin; DSS, dextran sodium sulphate; EM, electron microscopy; ENU, $N$-ethyl- $N$-nitrosourea; IBD, inflammatory bowel disease(s); MLN, mesenteric lymph node; SNP, single nucleotide polymorphism; UC, ulcerative colitis; UPR, unfolded protein response; vWF, von Willebrand factor; WT, wild type

* To whom correspondence should be addressed. E-mail: mmcguckin@ mmri.mater.org.au

¿ These authors contributed equally to this work.

a Current address: Australian National University Medical School, Canberra, Australia

\section{A B S T R A C T}

\section{Background}

MUC2 mucin produced by intestinal goblet cells is the major component of the intestinal mucus barrier. The inflammatory bowel disease ulcerative colitis is characterized by depleted goblet cells and a reduced mucus layer, but the aetiology remains obscure. In this study we used random mutagenesis to produce two murine models of inflammatory bowel disease, characterised the basis and nature of the inflammation in these mice, and compared the pathology with human ulcerative colitis.

\section{Methods and Findings}

By murine $\mathrm{N}$-ethyl- $\mathrm{N}$-nitrosourea mutagenesis we identified two distinct noncomplementing missense mutations in Muc2 causing an ulcerative colitis-like phenotype. $100 \%$ of mice of both strains developed mild spontaneous distal intestinal inflammation by $6 \mathrm{wk}$ (histological colitis scores versus wild-type mice, $p<0.01$ ) and chronic diarrhoea. Monitoring over 300 mice of each strain demonstrated that $25 \%$ and $40 \%$ of each strain, respectively, developed severe clinical signs of colitis by age $1 \mathrm{y}$. Mutant mice showed aberrant Muc2 biosynthesis, less stored mucin in goblet cells, a diminished mucus barrier, and increased susceptibility to colitis induced by a luminal toxin. Enhanced local production of IL-1 $\beta$, TNF- $\alpha$, and IFN- $\gamma$ was seen in the distal colon, and intestinal permeability increased 2 -fold. The number of leukocytes within mesenteric lymph nodes increased 5-fold and leukocytes cultured in vitro produced more Th1 and Th2 cytokines (IFN- $\gamma$, TNF- $\alpha$, and IL-13). This pathology was accompanied by accumulation of the Muc2 precursor and ultrastructural and biochemical evidence of endoplasmic reticulum (ER) stress in goblet cells, activation of the unfolded protein response, and altered intestinal expression of genes involved in ER stress, inflammation, apoptosis, and wound repair. Expression of mutated Muc2 oligomerisation domains in vitro demonstrated that aberrant Muc2 oligomerisation underlies the ER stress. In human ulcerative colitis we demonstrate similar accumulation of nonglycosylated MUC2 precursor in goblet cells together with ultrastructural and biochemical evidence of ER stress even in noninflamed intestinal tissue. Although our study demonstrates that mucin misfolding and ER stress initiate colitis in mice, it does not ascertain the genetic or environmental drivers of ER stress in human colitis.

\section{Conclusions}

Characterisation of the mouse models we created and comparison with human disease suggest that ER stress-related mucin depletion could be a fundamental component of the pathogenesis of human colitis and that clinical studies combining genetics, ER stress-related pathology and relevant environmental epidemiology are warranted.

The Editors' Summary of this article follows the references. 


\section{Introduction}

Intestinal goblet cells produce the viscous mucus layer covering the intestinal epithelium. In the large intestine mucus completely fills the crypts and forms a thick coating over the mucosal surface. MUC2 mucin is the major macromolecular constituent of intestinal mucus, and is responsible for its high viscosity and forming a protease-resistant matrix that retains molecules vital to host defence. MUC2 contains a large central O-glycosylated domain and $\mathrm{N}$ - and C-terminal cysteine-rich domains that homo-oligomerise [1], forming a complex molecular lattice [2,3]. MUC2 is N-glycosylated in the ER, where initial homo-oligomerisation occurs [4], and the complex then moves into the Golgi apparatus where O-glycosylation, the final stages of oligomerisation, and packaging into granules occur [5]. Mucins stored intracytoplasmically in granules form the characteristic goblet cell theca from where they are secreted constitutively and in response to stimuli.

Inflammatory bowel diseases (IBD), characterized by chronic or recurrent relapsing gastrointestinal inflammation, are broadly grouped by clinical and pathological features into two groups-Crohn's disease and ulcerative colitis (UC) [6-8]. Evidence from animal models indicates that failure to suppress immunity to the abundant intestinal foreign antigen load can cause inflammation. Maintaining the normal balance between competence to respond to intestinal pathogens while not generating an inflammatory response to commensals appears to depend on the integrity of the mucosal and epithelial barriers, proinflammatory signalling pathways (especially via $\mathrm{NF}-\kappa \mathrm{B})$, and regulation of innate and adaptive immune responses in the intestine and draining lymphoid organs. Disruption of any of these components has been shown to result in intestinal inflammation in animal models $[9,10]$. Defects in these components have been implicated in human IBD, although fundamental knowledge of underlying pathogenesis remains very poorly understood, with even the most well-established defect, CARD15 mutations, elucidating only a subset of white patients with ileal Crohn's disease $[9,10]$, and with a penetrance less than $4 \%$. Furthermore, the pathogenic pathways that distinguish UC from Crohn's disease remain obscure.

Goblet cell and secreted mucus phenotypes represent important differences between the two diseases: in Crohn's disease, there is typically an increase in goblet cells and a thicker mucus layer [11,12], whereas in UC there is a reduction in goblet cells, decreases in MUC2 production $[13,14]$ and sulfation [14-16], accumulation of MUC2 precursor [16], and a reduction in secreted mucus. Although it remains unclear whether changes in mucus are causative or secondary to inflammation [17], the lack of these changes in Crohn's disease indicate they are not a universal consequence of intestinal inflammation. Furthermore, a reduction in a specific biochemical fraction of colonic mucin has been described in UC patients and in their unaffected monozygotic twins [18,19], and engineered changes in intestinal mucin glycosylation result in enhanced susceptibility to toxininduced colitis [20], raising the possibility that genetic defects in mucin physiology or biochemistry predispose to UC. On the other hand, in $M u c 2^{-l-}$ mice the colitis phenotype appears to arise only on a permissive genetic background [21,22], and transgenic depletion of goblet cells not only does not trigger spontaneous inflammation, it unexpectedly reduces dextran sodium sulphate (DSS)-induced colonic injury [23]. Thus, a causal relationship between mucin abundance and colitis remains to be defined.

In this study we used random mutagenesis to produce murine models of inflammatory bowel disease. Two models were produced and we sought to characterize the basis for the pathology and identify similarities between these models and human IBD, particularly UC.

\section{Materials and Methods}

Generation of Mice by $N$-Ethyl-N-Nitrosourea Mutagenesis

All animal experimentation was approved by either the Australian National University or University of Queensland Animal Experimentation Ethics Committees. Mice were generated and housed in a PC2 specific pathogen-free facility and fed autoclaved food and water. For mutagenesis, we treated 8- to 15 -wk-old male C57BL/6 mice three times at weekly intervals with $85 \mathrm{mg} / \mathrm{kg} N$-ethyl- $N$-nitrosourea (ENU, Sigma-Aldrich) in $10 \%$ ethanol in citrate buffer ( $\mathrm{pH}$ 5.0). After identifying heritable phenotypes, affected $\mathrm{B} 6$ mice were outcrossed with NOD $\mathrm{H}-2^{\mathrm{k}}$ congenic mice, and the $\mathrm{F} 1$ mice were intercrossed. DNA from affected F2 mice was scanned using simple sequence length polymorphism markers and agarose gel electrophoresis. For experiments mice were housed either under SPF or clean conventional conditions and showed the same colitis phenotype in both housing conditions.

\section{Assessment of Inflammation and Intestinal Permeability}

Scoring of aberrant crypt architecture (score range 0-5), increased crypt length (0-3), goblet cell depletion (0-3), general leukocyte infiltration (0-3), lamina propria neutrophil counts (0-3), crypt abscesses (0-3), and epithelial damage and ulceration (0-3) was performed on the proximal and distal colon at 6,12 , and 18 wk of age (full details in Table S1). The mesenteric lymph nodes (MLNs) were dissected free of fat, disaggregated between two microscope slides, and the number of recovered leukocytes determined. $2 \times 10^{6}$ MLN leukocytes were cultured in $1 \mathrm{ml}$ of RPMI1640 containing $10 \%$ fetal calf serum and stimulated with $50 \mathrm{ng} / \mathrm{ml}$ PMA and $750 \mathrm{ng} / \mathrm{ml}$ ionomycin. The distal one-third of the colon was cleared of luminal material, weighed, washed four times in antibiotics, diced into $1 \mathrm{~mm}$ square pieces, and then cultured as explants for $24 \mathrm{~h}$ in $1 \mathrm{ml}$ of RPMI1640 containing $10 \%$ fetal calf serum. MLN and explant culture supernatants were frozen at $-70{ }^{\circ} \mathrm{C}$ until assayed for the inflammatory cytokines interleukin (IL)- $1 \beta$, tumour necrosis factor (TNF)- $\alpha$, interferon (IFN)- $\gamma$ (BD Biosciences), and IL-13 (R\&D Systems) according to the manufacturer's instructions. To assess intestinal permeability, mice were orally gavaged with $4 \mathrm{kDa}$ FITC-dextran (Sigma, $400 \mathrm{mg} / \mathrm{kg}$ body weight in PBS), blood samples obtained at 2 and $5 \mathrm{~h}$, and plasma FITC-dextran concentrations determined by measuring fluorescence at 520 $\mathrm{nm}$ emitted in a 96-well plate excited with a $474 \mathrm{~nm}$ laser using a FLA5100 scanner (Fuji) versus a FITC-dextran standard curve. Immunoglobulin coating of the faecal bacterial flora was determined using an adaptation of a flow cytometry technique used in human IBD [24].

\section{Induction of Colitis with Dextran Sodium Sulfate}

Mice were treated with $0.5 \%, 2 \%$, or $3 \%$ dextran sodium sulphate (DSS) in drinking water administered continuously for 3-63 d. Body weight, stool scores, and faecal occult blood 
were assessed daily. In $2 \%$ and $3 \%$ DSS experiments on day 7 blood was obtained for full blood counts and serum biochemistry, mice were humanely killed and dissected and the length of the large intestine was measured, and intestinal tissue was fixed for histological analysis. For assessment of DSS-induced inflammation, increased crypt length and goblet cell depletion were excluded from the colitis scores, because these parameters are fundamental components of the Winnie and Eeyore phenotypes. In the $0.5 \%$ DSS experiment, mice were weighed weekly, monitored daily, and humanely killed when too ill to continue based on a scoring system involving loss of body weight, diarrhoea, rectal prolapses and bleeding, behaviour, and appearance.

Antibodies, Immunohistochemistry, Immunofluorescence, and Western Blotting

Muc2 peptides (mM2.2, CPEDRPIYDEDLKK; mM2.3, NGLKPVRVPDADNC) were synthesized (Auspep), conjugated to BSA using glutaraldehyde, emulsified in Freund's adjuvant (Invitrogen), and used to immunize rabbits. Peptidespecific antibodies were purified from rabbit serum by affinity chromatography. The $4 \mathrm{~F} 1$ antibody reactive with the MUC2 nonglycosylated VNTR peptide repeat [25] was purified from hybridoma supernatant. We purchased antibodies against FLAG (Sigma, clone M2), GRP78 (Santa Cruz, polyclonal N-20), and $\beta$-actin (Novus Biologicals, clone AC15). Standard immunohistochemical procedures with HRPpolymer detection were used to detect MUC2 and GRP78. Standard immunofluorescence staining for Muc2 (detected with anti-rabbit Alexa 633, Invitrogen), the lectin Dolichos biflorus agglutinin (DBA, Sigma, detected with streptavidin Alexa 488, Invitrogen), and DAPI (Invitrogen) was analysed by multitracking on a LSM510 META confocal microscope (Zeiss). Standard PAGE (NuPAGE gels, Invitrogen) and Western blotting were performed with detection by chemiluminescence or dual-label infrared fluorescence on an Odyssey instrument (Li-Cor).

\section{Biochemical Characterization of Muc2}

Faecal matter was gently removed from the small and large intestines before the mucosa was scraped from the submucosa using a coverslip and extracted in ten volumes of $6 \mathrm{M}$ guanidine $\mathrm{HCl}$ extraction buffer, reduced, and alkylated as described [26], and subjected to agarose gel electrophoresis and Western blotting as described [27,28].

\section{Cloning and Expression of Recombinant Truncated Muc2 $\mathrm{N}$-Terminal Proteins}

The coding sequence for the murine $M u c 2 \mathrm{~N}$-terminal D3 domain (AJ511872 mRNA nucleotides 2452-3696, hereafter called rMuc2-D3) was reverse transcribed and amplified from murine intestinal RNA extracted from both wild-type C57BL/6 and Winnie mice using Platinum Pfx Taq polymerase (Invitrogen) and the following primers: 5'-CCCAAGCTTCCTTGCATCCA-

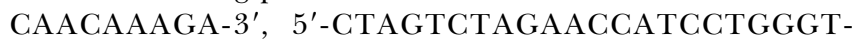
CATGTTAAG-3'. The amplicon was cloned into the HindIII and $\mathrm{XbaI}$ restriction sites of the pSecTag3xFLAG expression vector constructed by cloning three consecutive FLAG tags into the pSecTag vector (Invitrogen), establishing an $\mathrm{N}$-terminal signal peptide followed by 3 FLAG tags, and a C-terminal myc tag. Correct cloning was confirmed by sequencing. MKN45 cells were transfected with wild-type and Winnie rMuc2-D3 with
Lipofectamine 2000 (Invitrogen). After 48 h culture medium was replaced with serum-free medium for $24 \mathrm{~h}$ before collecting and concentrating it through a centrifugal membrane filter (Millipore). Cells were lysed in RIPA buffer and lysates subjected to Western blotting.

\section{Morphological Studies}

Intestinal tissue was fixed in $10 \%$ buffered formalin or frozen in OCT (Tissue Tek) and sections were stained with hematoxylin and eosin (H\&E), or with Alcian blue/Periodic Acid Schiff (PAS). For electron microscopy (EM) tissue was fixed in $4 \%$ glutaraldehyde, then post-fixed in osmium tetroxide, embedded in resin, and semi-thin sections stained with toluidine blue and thin sections with uranyl acetate.

\section{Gene-Expression Analysis}

RNA was extracted separately from the distal and proximal large intestine of three C57BL/6, three Winnie, and three Eeyore 8-wk-old mice using Trizol (Invitrogen) and cleaned on RNeasy columns (Qiagen). RNA integrity (RNA integrity number $>8$ ) was verified using a Bio-analyser (Agilent) and equal quantities of RNA from the proximal and distal large intestine of each mouse pooled. Samples were labelled for GeneChip analysis using the One-Cycle Target Labelling and Control Reagents (Affymetrix). All steps of target labelling, hybridisation, and scanning were performed according to the manufacturer's protocol. The entire microarray dataset can be accessed at NCBI GEO Accession No. GSE9913 (http:// www.ncbi.nlm.nih.gov/geo/) and a heat map of genes with altered expression is provided in Figure S1. For quantitative RT-PCR RNA was reverse-transcribed using Superscript III (Invitrogen) and amplified in a Rotor Gene RG-3000 (Corbett Life Science) using Platinum SYBR Green qPCR Supermix (Invitrogen) and the following cycling conditions and primers: $H s p a 5\left(95^{\circ} \mathrm{C} 10 \mathrm{~s} ; 56^{\circ} \mathrm{C} 20 \mathrm{~s}\right.$; and $72{ }^{\circ} \mathrm{C} 30$ s: $5^{\prime}$-TGCAGCAGGACATCAAGTTC- $3{ }^{\prime}$ and $5^{\prime}$ GTTTGCCCACCTCCAATATC- $3^{\prime}$ ), the unspliced isoform of XBP-1 $\left(95^{\circ} \mathrm{C} 10 \mathrm{~s} ; 60^{\circ} \mathrm{C} 45 \mathrm{~s}: 5^{\prime}\right.$ - CAGCACTCAGACTATGTGCACCTC- $3^{\prime}$ and $5^{\prime}$ - AAAGGATATCAGACTCAGAATCTGAAGA- $\left.3^{\prime}\right)$, the spliced isoform of $X b p-1\left(95{ }^{\circ} \mathrm{C} 10 \mathrm{~s} ; 60{ }^{\circ} \mathrm{C} 45 \mathrm{~s}: 5^{\prime}-\right.$ GAGTCCGCAGCAGGTGC- $3^{\prime}$ and $5^{\prime}$-CAAAAGGATATCAGACTCAGAATCTGAA- $\left.3^{\prime}\right)$ and $\beta$-actin $\left(94^{\circ} \mathrm{C} 10 \mathrm{~s} ; 53^{\circ} \mathrm{C} 30 \mathrm{~s}\right.$; $72{ }^{\circ} \mathrm{C} 30$ s: $5^{\prime}$-GAAATCGTGCGTGACATCAAA- $3^{\prime}$ and $5^{\prime}$ CACAGGATTCCATACCCAAGA-3' ${ }^{\prime}$ ).

\section{Assessment of Intestinal Hypertrophy and Apoptosis}

20 crypts cut in longitudinal section at each region of the intestine were measured using a micrometer. To determine the percentage of cells undergoing apoptosis, all of the epithelial cell nuclei within ten consecutive longitudinal crypt sections were counted together with the number of apoptotic bodies. Additionally, TUNEL staining was conducted with an In Situ Death Detection Kit according to the manufacturer's instructions (Roche Diagnostics) and photographed with an Olympus BX60 fluorescence microscope. To assess proliferation mice were given $100 \mu \mathrm{g} / \mathrm{g}$ body weight 5bromodeoxyuridine (BrdU) i.p. $2 \mathrm{~h}$ prior to killing for tissue removal. Sections from paraffin-embedded Swiss rolls of the small and large intestine were antigen-retrieved by heating for $20 \mathrm{~min}$ in $10 \mathrm{mM}$ citric acid $(\mathrm{pH} \mathrm{6)}$ and cooled to room temperature, then placed in $2 \mathrm{~N} \mathrm{HCl}$ for $60 \mathrm{~min}$ followed by boric acid-borate buffer ( $\mathrm{pH} \mathrm{7.6)}$ for $1 \mathrm{~min}$ and then $0.01 \%$ trypsin (in $0.5 \mathrm{M}$ Tris- $\mathrm{HCl}$ ) for $3 \mathrm{~min}$. Sections were then 
stained with the biotinylated anti-BrdU antibody and detected with streptavidin-HRP (BD Pharmingen). BrdUpositive and -negative nuclei were counted in ten crypts from proximal and distal colon and ten crypt-villus units from the small intestine.

\section{Human Tissue Samples}

For ultrastructural studies, intestinal tissue biopsies were obtained at colonoscopy from five female and three male patients; four of the total number had distal UC and four were unaffected individuals undergoing colorectal cancer screening. Paired biopsies from proximal and distal colon were taken for conventional H\&E histology and for EM. Two of the UC patients were on no treatment, one was on maintenance thiopurine and 5-aminosalicylate treatments, and the other was on a tapering dose of prednisolone. For immunohistochemistry, archival colonic biopsy tissue was prepared from five male and five female UC patients aged 24$45 \mathrm{y}$ with left-sided or extensive colitis. Three had colitis in complete endoscopic remission (one with no immunosuppressive or 5-aminosalicylate treatment), four had mild colitis (three no treatment), and three had moderately severe colitis (one no treatment). Immunohistochemical detection of the Muc2 and the ER chaperone protein GRP78 was conducted using paraffin sections from these ten UC patients and normal tissue obtained from resection margins of patients undergoing surgery for colorectal cancer. The collection of tissue and clinical data followed informed consent and was approved by the Mater Health Services Human Research Ethics Committee Approval No. 396A.

\section{Statistical Analyses}

Due to difficulties in verifying normality of distributions when the sample size is small, we have taken a conservative approach and used the nonparametric Mann-Whitney U-test or Kruskal-Wallis test with Dunn's multiple comparison test for multiple comparisons, and data are presented using box plots. For larger datasets $(n>10)$, data were assessed with probability plots to determine if they were normally distributed prior to parametric analysis by ANOVA followed by the Bonferroni post-hoc test. Survival analysis was conducted using Kaplan-Meier plots and the Mantel log-rank test. All statistical analyses were performed using Prism v4.03 (Graphpad Software) or Systat v10.2 (Systat Software). The statistical test used and the sample sizes for individual analyses are provided within the figure legends.

\section{Results}

\section{Identification of Two Novel Goblet Cell Mutants}

We identified Winnie mice amongst the G3 progeny of an ENU-treated C57BL/6 founder by their visible phenotype of spontaneous watery diarrhoea and high incidence of rectal bleeding and prolapse. Compared with wild-type littermates, Winnie small and large intestines were characterized by fewer goblet cells with smaller thecae, the presence of PAS-positive Alcian blue-negative material in the cytoplasm, and a reduction in secreted mucus (Figure 1). This phenotype differs from $M u c 2^{-1-}$ mice, which completely lack Alcian bluepositive mucin stored in goblet cells and secreted mucus [21]. In order to map Winnie, we outcrossed an affected G4 to $\mathrm{NOD}^{\mathrm{k}}$ mice, and intercrossed their F1 progeny; 46/172 (27\%)
F2 mice had the diarrheal phenotype, consistent with a fully penetrant recessive trait (Figure 2A). Genotyping of 19 affected mice for a panel of 115 microsatellite markers mapped the mutation to a $14.5 \mathrm{Mb}$ interval on Chromosome 7 encoding 198 transcripts including the Muc2 and Muc6 mucin genes (Figure 2B). We sequenced exons for the two mucin genes and found a single missense mutation (G9492A, GenBank accession no. AJ511872, http://www.ncbi.nlm.nih. gov) resulting in substitution of cysteine with tyrosine in the D3 domain at the $\mathrm{N}$ terminus of Muc2 (Figure 2C).

The possibility existed that another, unidentified mutation might be present to explain Winnie. We identified a second strain, Eeyore, from a different G0 founder, with a similar phenotype also inherited as a fully penetrant recessive trait (Figure 2D). In a Win/Win $\times$ Eey/ + complementation test, eight of 22 offspring exhibited the clinical and histopathological phenotype (Figure 2D). Thus, the noncomplementation of Winnie with Eeyore provided strong evidence that both strains harbour a mutation in the same gene and that these mutations are solely responsible for the phenotype. Sequencing of $M u c 2^{\text {Eey }}$ identified a unique missense mutation (T2996C, GenBank accession no. AJ511873) resulting in a serine to proline substitution in the C-terminal D4 domain (Figure 2C). Winnie and Eeyore remain the only characterized diarrheal/ colitis phenotypes in the Australian Phenomics Facility and Phenomix Australia murine ENU mutagenesis programs.

\section{Muc2 Mutant Mice Develop Spontaneous Colitis}

The progressive incidence of rectal prolapse and colitisassociated mortality in Winnie and Eeyore mice is shown in Figure 3A. At 1 y approximately $40 \%$ of Eeyore and $25 \%$ of Winnie mice had died or were humanely killed due to the development of rectal prolapse or debility (based on a multifactorial scoring system, see Materials and Methods), whereas no wild-type littermates developed rectal prolapses. Proximal and distal colon were thickened and colon weight was greater in Winnie and Eeyore than in wild-type mice, and the thickening and weight increased progressively from 6 to 18 wk of age (Figure 3B). Despite its thickening, the colon was not shortened in mutant mice (Figure S2). Colitis was assessed histologically in Winnie mice at 6, 12, and 18 wk of age, revealing mild inflammation in the large intestine (Figure 3C). The inflammatory infiltrate was usually mild and did not become more severe with age. Classical signs of murine colitis, including crypt elongation, neutrophilic infiltrates, goblet cell loss, crypt abscesses, and focal epithelial erosions were present, particularly in the distal large intestine (examples shown in Figure 3F-3K).

\section{Extreme Susceptibility to Induced Inflammation in Mice with Muc2 Mutations}

In addition to spontaneous inflammation, Winnie and Eeyore mice exhibited increased susceptibility to environmentally induced colitis. Low doses of luminal toxins ( $0.5 \%$ DSS) resulted in rapid weight loss and lethal ulcerating colitis in Winnie by day 30 , whereas wild-type mice gained weight and survived for at least $9 \mathrm{wk}$ (see Figures 4A and S3). After 2\% DSS, Winnie and Eeyore showed earlier faecal occult blood than did wild-type mice (after exclusion of mice with spontaneous rectal bleeding or prolapses), and higher histological colitis scores after $3 \mathrm{~d}$ (Figure 4B), whereas by day 7 colitis scores in wild-type mice were closer to those of 


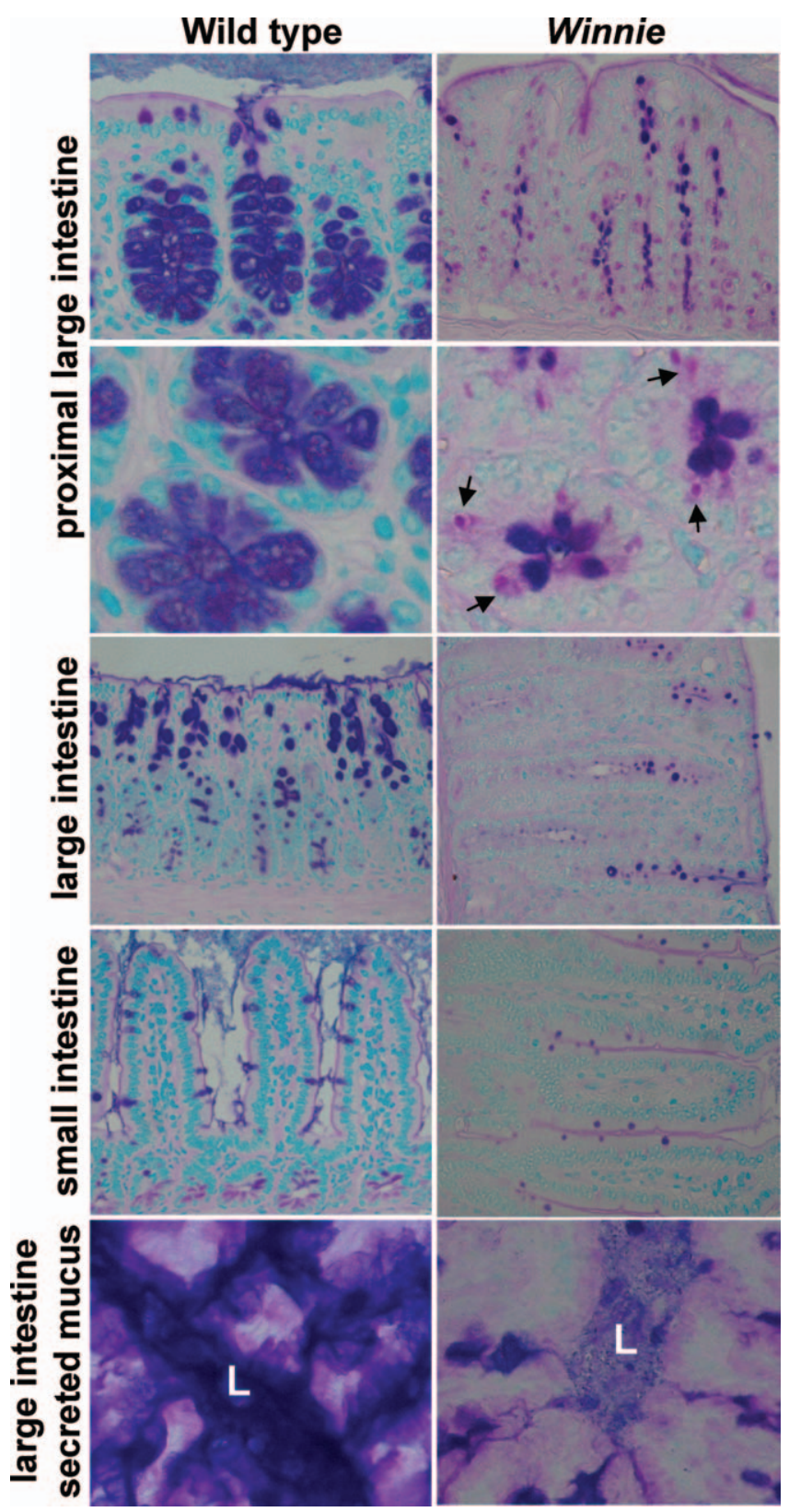

Figure 1. Histological Phenotype of Mice with Muc2 Mutations

PAS/Alcian blue stained intestinal sections from Winnie and wild-type $\mathrm{C} 57 \mathrm{BL} / 6$ mice. Note the reduced size of Alcian blue staining thecae (stored mucin) and the presence of PAS-positive/Alcian blue negative accumulations (arrows) in Winnie goblet cells. L, lumen.

doi:10.1371/journal.pmed.0050054.g001

mutant mice. Colitis was more pronounced in the large intestine, although some damage and inflammation were also seen in the terminal ileum (Figure S3). Although DSS is often thought to induce only colonic inflammation, damage in the ileum has been reported [29]. After oral 3\% DSS for $7 \mathrm{~d}$, Winnie mice exhibited more severe colitis than did wild-type controls, based on rate and extent of weight loss, colon length, changes in stool scores, haematocrit, blood haemoglobin, and leukocyte counts (Figures 4C and S4). All Winnie colons contained a massive mixed inflammatory infiltrate and almost total loss of colonic epithelium compared with much milder and intermittent colitis in wild-type mice (Figure S3).
Winnie heterozygotes exhibited increased rectal bleeding in response to DSS, indicating that these mutations are not simple recessive mutations under environmental stress. On day 4 , only one in five wild-type mice showed rectal bleeding compared to five of five Winnie and five of five heterozygous mice. Mean haematocrits on day 7 were $41 \%$ for wild-type versus $28 \%$ for Winnie mice and $29 \%$ for heterozygotes (Figure 4C).

\section{Increased Intestinal Proliferation and Apoptosis in Mice with Muc2 Mutations}

Both Winnie and Eeyore mice showed crypt elongation throughout the large intestine (Figure 5A) suggesting increased epithelial proliferation. This possibility was confirmed by increased BrdU incorporation in the proximal and distal colon but not in the small intestine (Figure 5B and 5C). TUNEL staining and quantitative assessment of apoptotic cells indicated that the decrease in goblet cell number (Figures 1 and 2D) in the two mutants was due to increased apoptosis in the distal colon as well as in the small intestine, caecum, and proximal and distal colon of Winnie mice (Figure $5 \mathrm{D}$ and $5 \mathrm{E}$ ). Consistent with these morphological findings, comparison of the intestinal transcriptome (see Table S2) of Winnie, Eeyore, and wild-type mice revealed altered expression of molecules associated with regulation of epithelial growth and wound repair (increased secretory leukocyte peptidase inhibitor, epiregulin, amphiregulin, heparin-binding epithelial growth factor, lipocalin-2, stratifin, and the receptor for hyaluronan-mediated motility), cell cycle progression (increased cyclin B1 and p21), and apoptosis (increased intectin and RIP3 kinase, decreased $\mathrm{Bcl}$ ). In contrast to Winnie and Eeyore mice, while $M u c 2^{--}$mice also showed elongated crypts and increased mitosis, their rate of epithelial apoptosis was decreased compared to wild type [21]. Unlike $M u c 2^{-l-}$ mice, neither Winnie nor Eeyore developed spontaneous intestinal tumours [21] nor did they show growth retardation [22].

\section{Altered Muc2 Expression in Mice with Muc2 Mutations}

Muc2 mRNA concentrations were decreased in the large intestine 2.3-fold in both Winnie and Eeyore compared to wildtype mice, consistent with fewer goblet cells and/or transcriptional repression of Muc2 (see Table S3). Muc2 protein was also decreased in intestinal extracts of both Winnie and Eeyore, consistent with decreased production and/or decreased stability of secreted Muc2 (Figure 6A). Compared with the wild-type protein, migration of mutant Muc2 during agarose gel electrophoresis was more diffuse, consistent with altered glycosylation or reduction-insensitive oligomerisation.

In addition to quantitative and qualitative changes in secreted Muc2, the distribution of the mucin within the goblet cells was abnormal in Winnie and Eeyore. By immunohistochemistry (using mM2.2, a Muc2 N-terminal peptide antibody that binds independently of mucin glycosylation) Muc2 is normally confined to the thecae of goblet cells, where the mature glycosylated molecule is stored prior to secretion (Figure 6B). By contrast, in both Winnie and Eeyore mice, goblet cell thecae were smaller and fewer, and Muc2 was also present within the cytoplasm distinct from thecal structures (Figure 6B). Identical staining was seen with a C-terminal antibody (mM2.3, unpublished data). In addition, diffuse accumulations of Muc2 were seen in cells otherwise not recognizable as goblet cells because they lacked thecae, a 


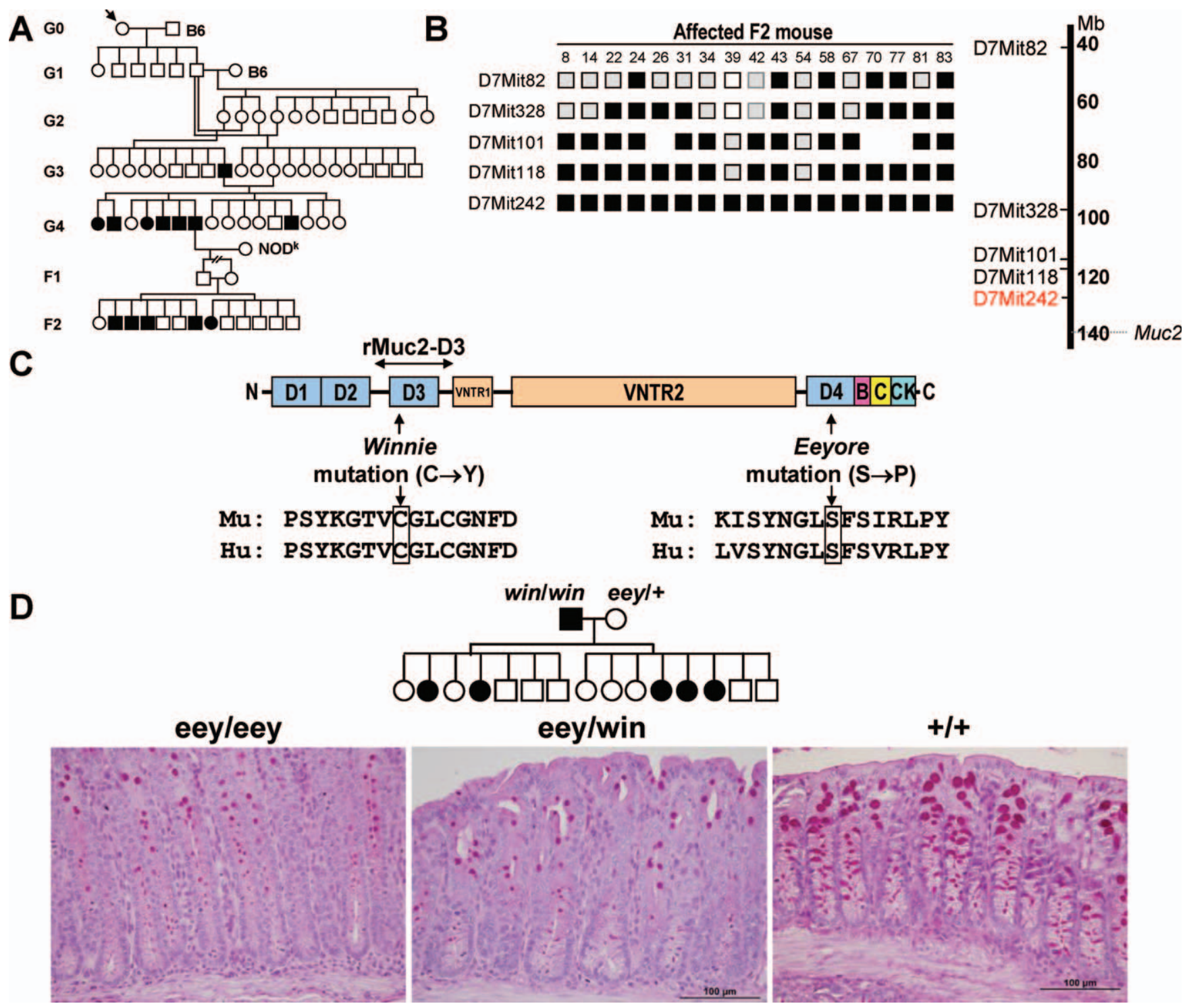

Figure 2. Generation and Characterization of Mice with Muc2 Mutations

(A) Dendrogram showing genesis of the Winnie mutation; filled symbols indicate the diarrhoea phenotype.

(B) Microsatellite genotype on Chromosome 7 of 17 affected Winnie F2 mice.

(C) Domain organization of the Muc2 protein showing the $\mathrm{N}$ - and C-terminal vWF D-domains (D1-D4), the C-terminal B, C, and CK domains, and the two central glycosylated tandem repeat domains (VNTR). The sites of the Winnie and Eeyore mutations are shown, together with the region cloned to express the rMuc2-D3 recombinant protein.

(D) Results of complementation cross of Win/Win and Eey/t. PAS-stained sections of representative distal large intestinal histological phenotypes demonstrate noncomplementation (preservation of the eey/eey histological phenotype in eey/win). doi:10.1371/journal.pmed.0050054.g002

morphological finding that has also been reported in human UC $[16,30,31]$.

In the proximal to mid-colon there are two distinct lineages of mucus-producing cells of differing morphology [32]. Both expressed Muc2 and exhibited the altered cellular distribution of Muc2 protein in the mutant mice, although this distribution was more pronounced in the longer-lived goblet cells at the base of the crypts. Although the entire colon and small intestine of the mutant mice harboured affected goblet cells, some areas of the colon showed greater goblet cell depletion/reduction in thecae, suggesting that the local microenvironment can exacerbate this phenotype.

Finally, we used confocal microscopy to assess mucin glycosylation using dual-label immunofluorescence labeling with the mM2.2 Muc2 antibody and the DBA lectin, which recognizes an O-linked sugar, $\alpha \mathrm{D}$-GalNAc, present on Muc2 in the small intestine and proximal to mid-colon. In wild-type proximal colon, Muc2 was confined to the thecae and was $\mathrm{O}-$ glycosylated (DBA lectin-positive; note that DBA lectin also reacted with some other glycoproteins in the glycocalyx and within the cytoplasm [Figure 6C]). In Winnie and Eeyore mice, where goblet cell thecae were present they contained glycosylated (DBA lectin-positive) Muc2. However, in addition, prominent cytoplasmic accumulations of non-O-glycosylated (DBA lectin-negative) Muc2 were seen within wellcircumscribed vacuolar structures in virtually all goblet cells, including in some cells lacking clear goblet cell thecae (Figure 6C). These accumulations were most prominent in goblet 

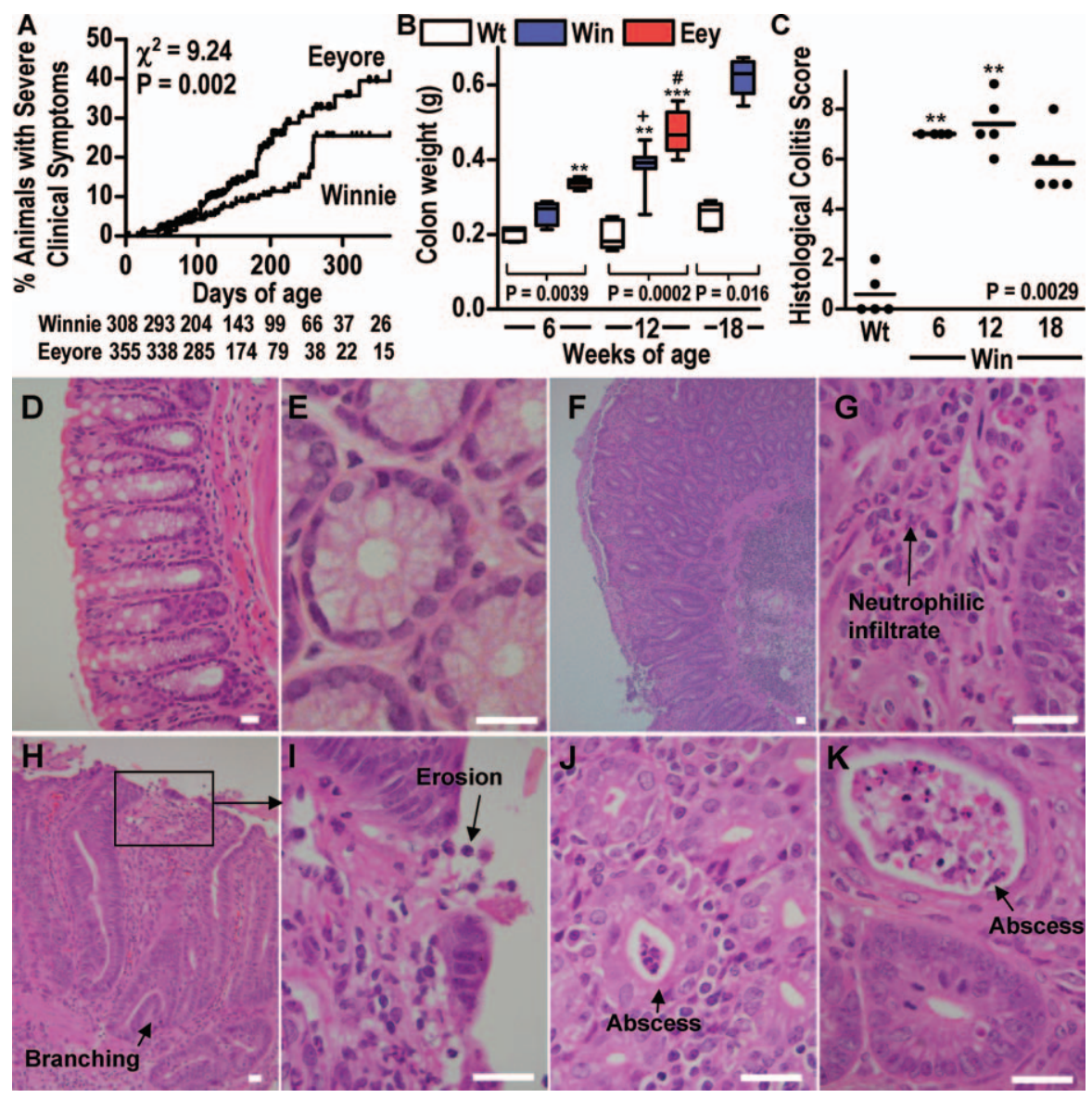

Figure 3. Spontaneous Colitis in Mice with Muc2 Mutations

(A) Incidence of premature death or colitis-associated pathology requiring humane killing (chiefly rectal prolapse) in Winnie $(n=309)$ and Eeyore $(n=$ 355) mice. Mice entering experiments or killed for other reasons were treated as censored observations (designated by upward ticks), and the number of uncensored mice remaining at $50 \mathrm{~d}$ intervals is included underneath the graph. Incidence rates in the two strains were compared using the Mantel Log-rank test.

(B) Weight of the colon after removal of luminal faecal material in C57BL/6 (WT), Winnie (Win), and Eeyore (Eey) mice at 6 (Eey 6-9 wk), 12, and 18 (WT and Win only) wk of age, $n=4-9$; box plots show median, quartiles, and range.

(C) Histological colitis scores (see Materials and Methods) in WT and Win mice at 6, 12, and 18 wk of age, $n=4-6$; scores from individual mice are shown. (D-K) Histology of normal distal colon from a C57BL/6 mouse (D and E) and examples of inflammation in the rectum (F-I) and distal large intestine ( $J$ and K) of untreated Winnie mice showing leukocytic infiltration ( $\mathrm{G}$ and $\mathrm{I})$, occasional branching crypts ( $\mathrm{F}$ and $\mathrm{H}$ ), crypt abscesses ( $\mathrm{J}$ and $\mathrm{K}$ ) and focal ulcerations (I); scale bars $=20 \mu \mathrm{m}$. Note the layer covering the mucosal surface in $(\mathrm{F})$ is a granulocytic serous exudate.

Statistics (B and C): $p$-values for Kruskal-Wallis nonparametric analysis are shown, Dunn's multiple comparison test versus wild type, ${ }^{* *} p<0.01,{ }^{* * *} p<$ 0.001 ; versus Win at $6 \mathrm{wk}^{+} p<0.05$; versus Eey at $6 \mathrm{wk},{ }^{\#} p<0.05$.

doi:10.1371/journal.pmed.0050054.g003

cells in the base of the crypts in the proximal colon, but were seen in all other Muc2-producing goblet cells throughout the small and large intestine (Figure S5). Generally, accumulations were more prominent in Eeyore than in Winnie mice. Some apoptotic cells shed into the lumen contained Muc2positive DBA lectin-negative vacuoles consistent with apoptosis of goblet cells. Notwithstanding the accumulation of Muc2 precursor, immunohistochemistry and immunofluorescence confirmed that some goblet cells were actively secreting glycosylated Muc2 in both strains of mutant mice and that Muc2 was present within luminal secretions.

\section{Hyperoligomerisation of Mutant Muc2 Protein}

Muc2 is secreted as an insoluble gel that is not suitable for biochemical analyses without reduction, and reduction prevents analysis of oligomerisation. Additionally, the complete $M u c 2$ cDNA is too large $(>15 \mathrm{~kb})$ to express in vitro. Therefore, to ascertain whether the Winnie mutation affects biosynthesis of Muc2, we cloned partial cDNAs encoding the Winnie and wild-type Muc2 N-terminal D3 oligomerisation domain (rMuc2-D3, Figure 2C) and expressed these as recombinant proteins in MKN45 gastric cancer cells which produce the MUC5AC mucin (but not MUC2) and are therefore likely to express mucin-specific chaperones. Western blotting of cell lysates demonstrated increased oligomerisation of the D3 proteins carrying the Winnie mutation (Figure 7). Wild-type D3 proteins were present intracellularly mainly as monomers and dimers, with a small amount of tetramer $(11 \%)$. In contrast, $61 \%$ of Winnie D3 proteins were in the form of a ladder of higher-order oligomers. Wild-type D3 proteins were secreted from MKN45 cells almost exclusively as dimers with a small tetramer band, whereas, despite production intracellularly, Winnie D3 proteins were not secreted, thus confirming the mutation leads to a defect in biosynthesis or secretion. 

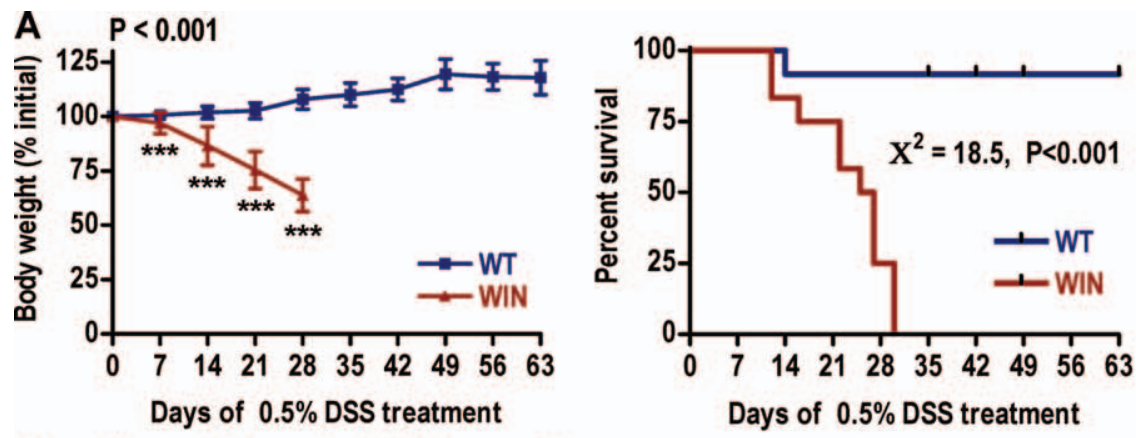

B $\quad \mathrm{NI}=$ no inflammation (all mice score 0 ) Terminal ileum
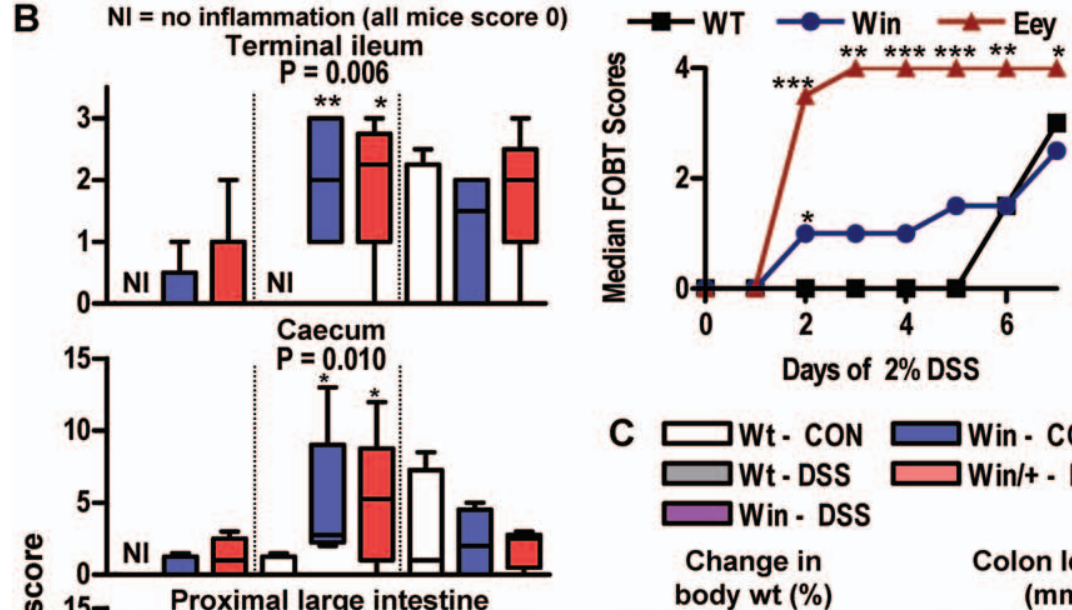

C
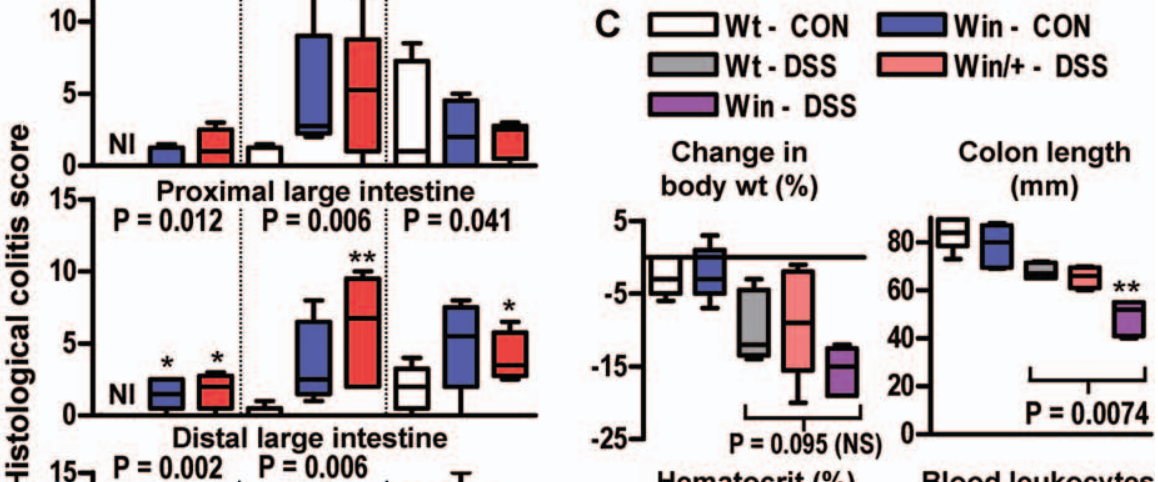

Colon length

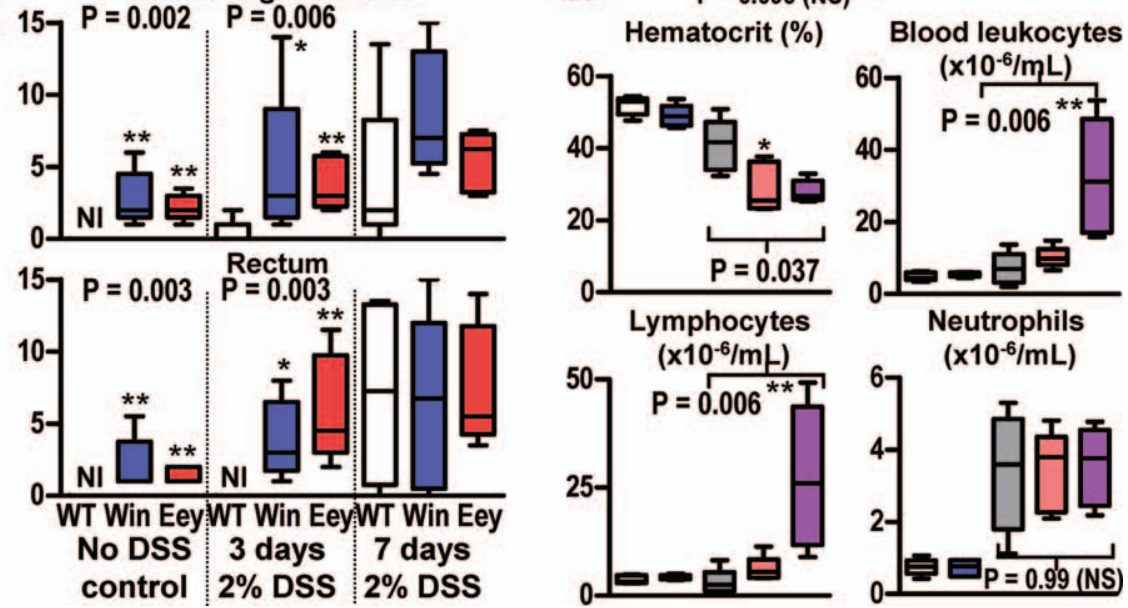

Figure 4. Susceptibility of Mice with Muc2 Mutations to Dextran Sodium Sulphate-Induced Colitis

(A) Wild-type (WT) C57BL/6 and Winnie (Win) mice $(n=12)$ were given $0.5 \%$ DSS in drinking water for 63 d. Body weight (mean \pm standard deviation, ANOVA $p$-value shown, Bonferroni's post-hoc test versus wild-type mice, ${ }^{* * *} p<0.001$ ) and overall survival (Kaplan-Meier survival estimates and Mantel log-rank test $\left[\chi^{2}\right.$-value $\left.]\right)$ are shown.

(B) Wild-type C57BL/6 (WT), and Winnie (Win), and Eeyore (Eey) mice not manifesting rectal bleeding or prolapse $(n=6)$ were given $2 \%$ DSS in drinking water or water alone for $7 \mathrm{~d}$. Histological colitis scores were determined on days 3 and 7 and faecal occult blood determined daily. Statistics: box plots show median, quartiles, and range; $p$-values for Kruskal-Wallis nonparametric analysis are shown, Dunn's multiple comparison test versus WT, * $p<$ $0.05, * * 0<0.01 * * * * 0.001$.

(C) Wild-type C57BL/6, Winnie, and Winnie heterozygous (Win/+) mice $(n=5)$ were given $3 \%$ DSS in drinking water or drinking water alone (CON) for $7 \mathrm{~d}$, at which time body weight, colon length, and haematology were assessed. Statistics: box plots show median, quartiles, and range; $p$-values for KruskalWallis nonparametric analysis comparing DSS-treated WT, Win/+, and Win mice are shown, Dunn's multiple comparison test versus WT, ${ }^{*} p<0.05,{ }^{* *} p$ $<0.01$; NS, not significant. Additional data from these experiments are shown in Figures S2 and S3.

doi:10.1371/journal.pmed.0050054.g004 


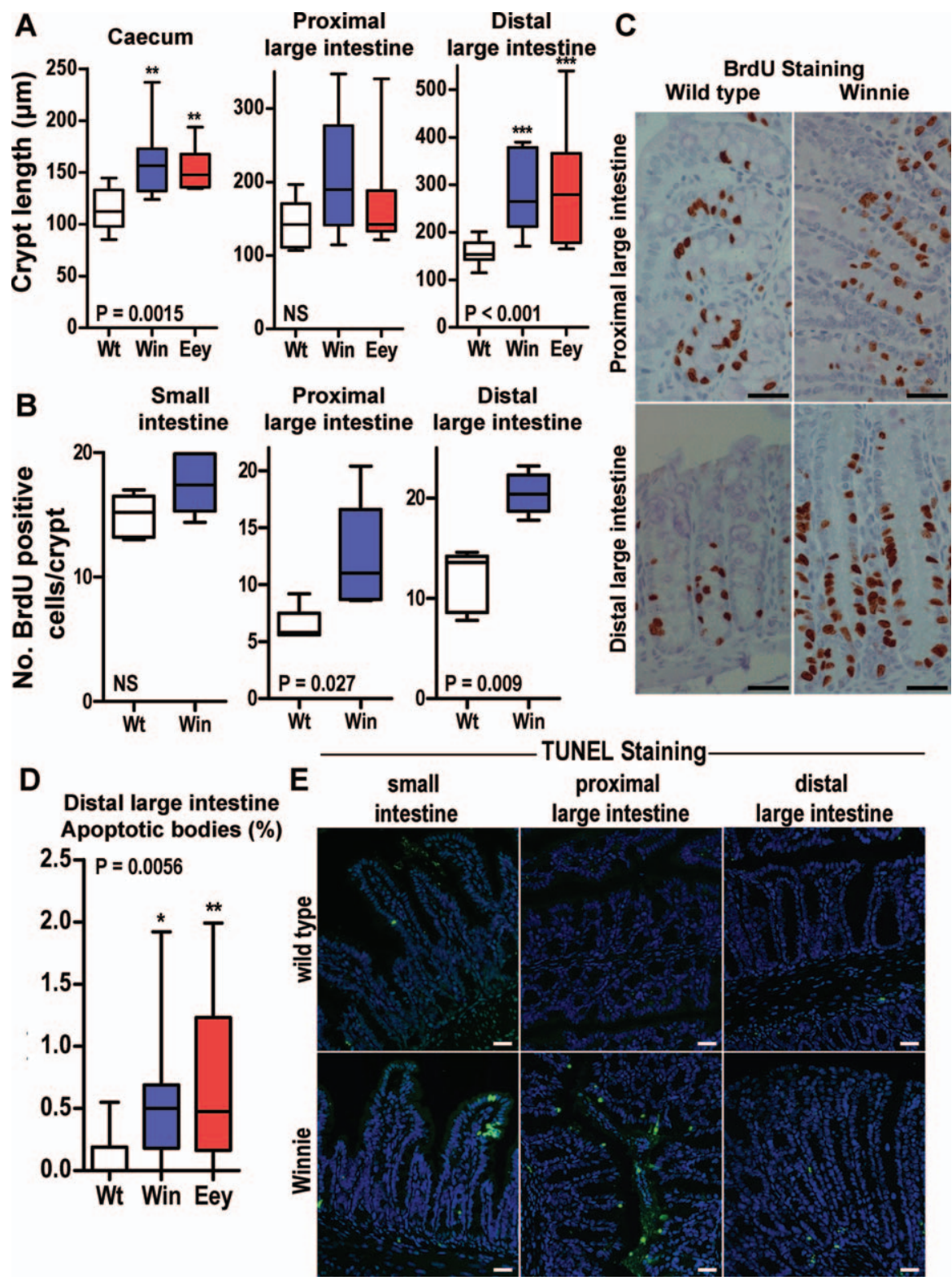

Figure 5. Intestinal Proliferation and Apoptosis Are Increased in Mice with Muc2 Mutations

(A) Length of caecal, proximal, and distal large intestinal crypts in wild-type C57BL/6 (WT, $n=12)$, Winnie (Win, $n=11)$, and Eeyore (Eey, $n=14)$ mice. (B) Assessment of incorporation of BrdU in the small intestine, and proximal and distal large intestine of WT $(n=5)$ and Win $(n=5)$ mice. For each region of the intestine in each mouse the number of BrdU-positive nuclei was counted in ten crypts (see Materials and Methods).

(C) Representative examples of BrdU staining in the proximal and distal colon.

(D) Increases in the percentage of apoptotic bodies in distal large intestinal crypts of the same mice as in (A).

(E) TUNEL staining showing increased apoptosis in the small and large intestine of Winnie mice (images representative of three mice in each group). Scale bars $(C$ and $E)=50 \mu \mathrm{m}$. Statistics: box plots show median, quartiles, and range; $(A, B$, and $D)$ Kruskal-Wallis nonparametric analysis ( $p$-values shown) with Dunn's multiple comparison test $\left({ }^{*} p<0.05,{ }^{* *} p<0.01,{ }^{* * *} p<0.001\right)$; (B) Mann-Whitney U-test, $p$-values shown. NS, not significant. doi:10.1371/journal.pmed.0050054.g005

\section{Muc2 Mutations Lead to Accumulation in the ER}

Both Muc2 mutations result in a reduction of Muc2 secretion and altered oligomerisation, but the presence of cytoplasmic accumulations of Muc2 precursor raised the possibility of additional pathogenic effects. Since alterations resulting from point mutations can result in functional and sometimes toxic effects not observed when the protein is absent, such effects could contribute to the phenotype of Winnie and Eeyore and explain differences of these mutants from $M u c 2^{--}$mice. To this end, we next examined both mutant strains for ultrastructural changes. Resin sections revealed that Winnie and Eeyore small and large intestines contained large numbers of cells distended with membranous vacuolar material, corresponding with the areas in which Muc2 precursor was detected by confocal microscopy. Vacuolisation was more frequent in the large intestine, and vacuolated cells usually contained stored mucin granules in thecae, demonstrating that they were goblet cells, although these thecae were smaller than in wild-type goblet cells (Figure 8A, 8E, 8I, 8M, 8P, and 8S). By transmission EM, goblet cells possessed dilated rough ER containing aggregates of variable electron density, which is the ultrastructural appear- 


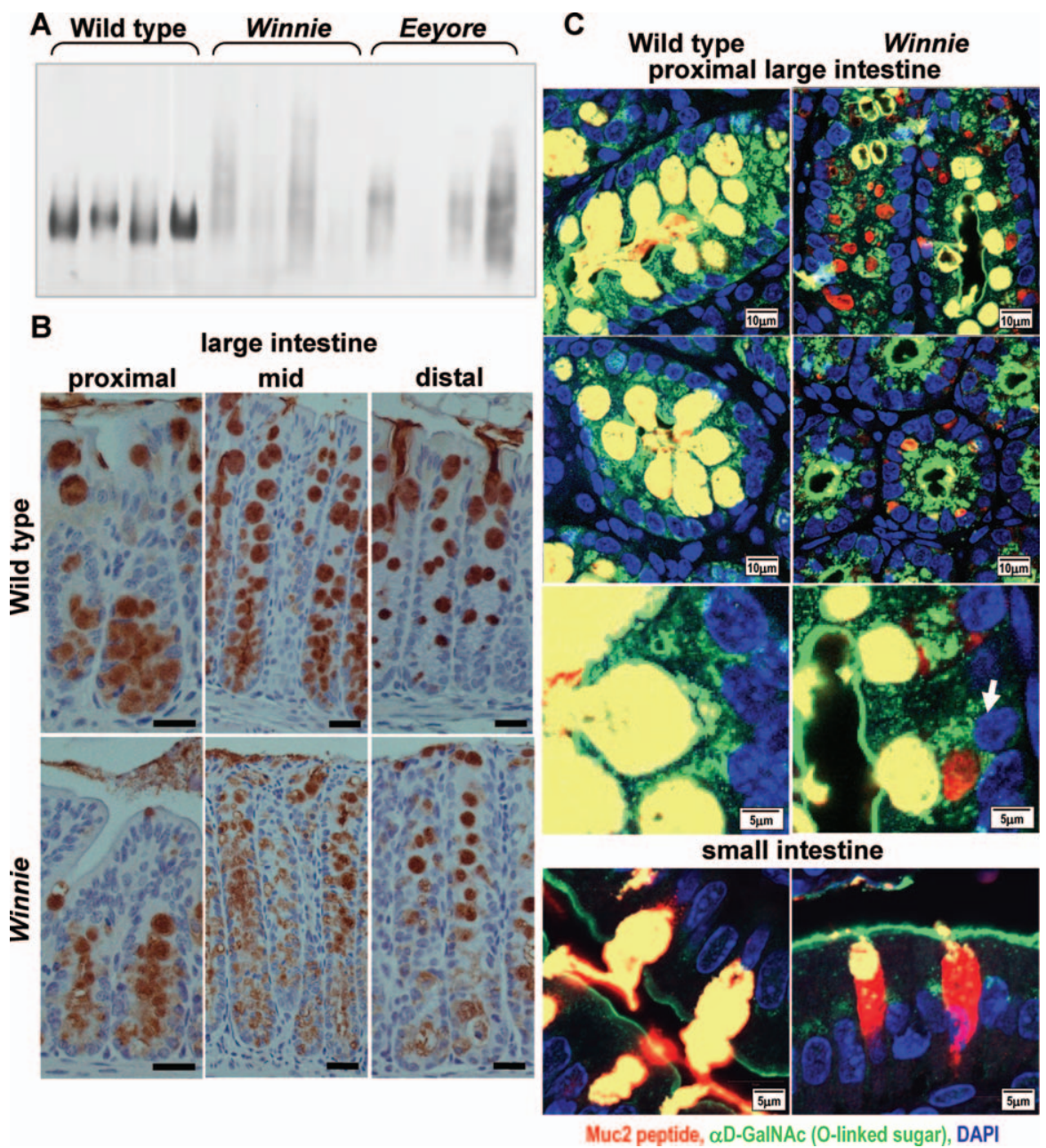

Figure 6. Altered Muc2 Protein Expression in Mice with Muc2 Mutations

(A) Muc2 proteins from wild-type, Winnie, and Eeyore intestinal extracts were reduced and separated by agarose gel electrophoresis and detected by Western blotting with the mM2.2 antibody. Note the reduced intensity and the altered electrophoretic migration in the mutant proteins.

(B) Cellular localization of Muc2 in wild-type and Winnie colon tissue determined by immunohistochemistry with affinity purified mM2.2 antibody. Note the decreased size of goblet cell thecae and cytoplasmic Muc2 staining outside thecae in Winnie; scale bars $=25 \mu \mathrm{m}$.

(C) Confocal microscopy of wild-type and Winnie goblet cells from the proximal colon and small intestine showing vacuolar accumulation of Muc2 (red) lacking O-linked sugars identified with the DBA lectin (green) in Winnie only. Goblet cell thecae appear yellow due to merging of the red Muc2 core peptide with the green O-linked sugar. Nuclei are stained with DAPI (blue). Scale bars as marked. Single colour images of these composites are provided in Figure S5A-S5C.

doi:10.1371/journal.pmed.0050054.g006

ance of protein misfolding and ER stress (Figures $8 \mathrm{~F}-8 \mathrm{H}, 8 \mathrm{~J}-$ $8 \mathrm{~L}, 8 \mathrm{Q}, 8 \mathrm{R}, 8 \mathrm{~T}$, and $8 \mathrm{U})$. The size and extent of these ER accumulations varied; cells with more were substantially distended, usually lacked stored mucin granules and often contained swollen mitochondria with disrupted cristae (Figure 8V). The two distinct lineages of mucus-producing cells in the proximal colon both showed vacuolisation, although vacuoles were more extensive in the longer-lived lineage that resides in the base of the crypts [32]. Some vacuoles were surrounded by membranes lacking ribosomes, possibly representing accumulations in the Golgi apparatus. Vacuole accumulation was restricted to Muc2-producing cells, with most nongoblet epithelial cells showing normal ultrastructure. However, some enterocytes and Paneth cells also contained ER vacuoles, although these vacuoles were fewer and smaller than in goblet cells, consistent with the comparatively low levels of Muc2 production that we observed in these cells by immunohistochemistry (Figure $8 \mathrm{X}$ ).
Given the increased susceptibility of heterozygous mice to DSS, to assess whether one mutant allele could initiate ER stress we examined heterozygous mutants. These mice lacked the diarrhoea phenotype, and their intestinal morphology appeared normal by standard light microscopy. However, glutaraldehyde fixation and resin embedding revealed variable, though often extensive, vacuolisation in goblet cells deep in the crypts of the proximal colon (Figure 9), demonstrating subclinical pathology and establishing that these mutations are not simple mendelian recessive traits. In heterozygotes the surface goblet cell lineage in the proximal colon and the morphologically similar goblet cells in the distal colon and small intestine were mostly free of vacuolisation (Figure 9). However, vacuoles were present in some Paneth cells in the small intestine despite their lower level of Muc2 production, which may be due to the extended lifespan of these cells (unpublished data).

Accumulation of nonglycosylated Muc2 precursor (Figure 

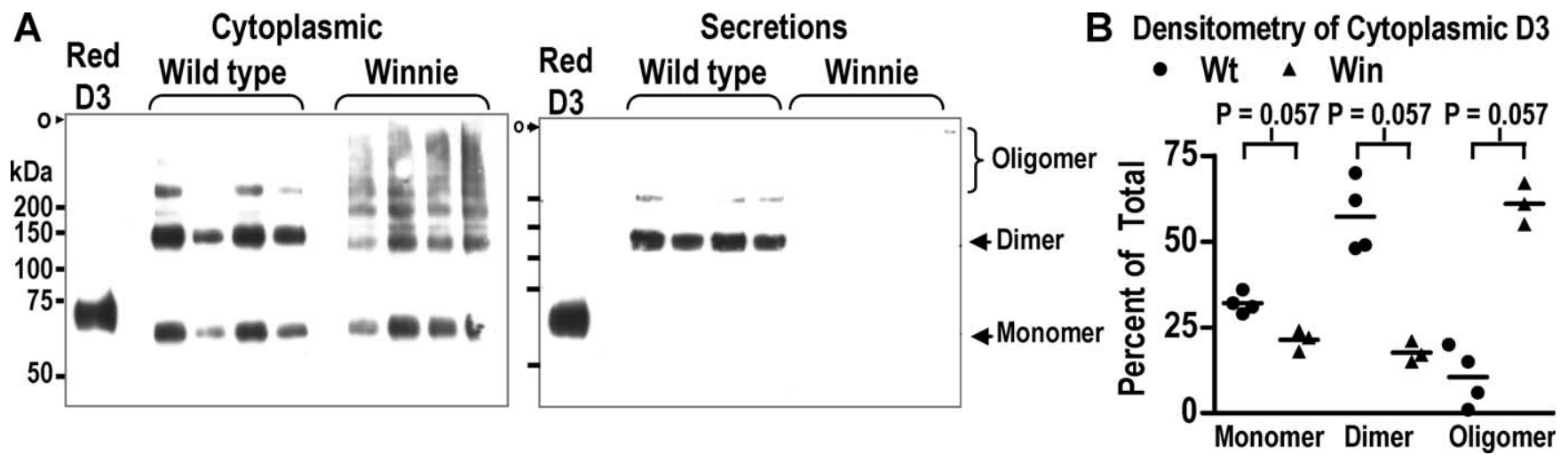

Figure 7. Altered Muc2 N-Terminal Oligomerisation Caused by the Win Mutation

(A) PAGE/Western blotting analysis of oligomerisation of the rMuc2-D3 wild-type proteins and proteins with the Win mutation in MKN45 cells and secretions following transfection ( $n=4$ separate transfections for each group). The position of the origin (o) and markers are shown. A reduced sample (D3 Red) on each gel shows the migration of the D3 monomer. Recombinant proteins were detected with the M2 anti-FLAG antibody, and no reactivity was seen with untransfected cells. Note the hyperoligomerisation of the Winnie D3 domain intracellularly and its failure to be secreted.

(B) Densitometric analysis of oligomerisation of the rMuc2-D3 Winnie and wild-type proteins in MKN-45 cellular lysates following transfection. Relative expression of monomer, dimer, and higher-order oligomers was determined by densitometry and expressed as a percentage of the total densitometric value for each sample (lane).

Statistics: individual data points and $p$-values from Mann-Whitney U-tests shown.

doi:10.1371/journal.pmed.0050054.g007

6C), altered electrophoretic migration (Figure 6A), ER vacuolisation (Figure 8), and the hyperoligomerisation of the Winnie D3 domain (Figure 7) together demonstrate that a proportion (but not all) of Muc2 produced in Winnie and Eeyore goblet cells is inappropriately assembled, accumulates in the ER, and leads to ER vacuolisation, smaller goblet cell thecae, and reduced secretion of mature Muc2. It appears that at some stage of their life cycle these goblet cells cease producing mature mucin, whilst still retaining Muc2 precursor in ER vacuoles (see middle right image of large intestine in Figure 6C).

\section{Aberrant Mucin Assembly Triggers an ER Stress Response}

GRP78 is a heat shock protein that chaperones proteins in the ER during folding and is up-regulated in ER stress when it accumulates with misfolded proteins, ensuring they do not exit the ER normally but are removed for degradation [33]. Quantitative PCR showed a 2- to 3-fold increase in Hspa5 (which encodes GRP78) mRNA in Winnie and Eeyore proximal and distal colon (Figure 10A). Protein misfolding engages a series of molecular events that result in reduced protein translation and transcription of genes involved in the unfolded protein response (UPR) [34]. Splicing of the $X b p-1$ mRNA by the enzyme IRE-1 is one key component of the UPR and we observed significantly decreased levels of the unspliced form of $X b p-1$ in the proximal colon of Winnie and increased levels of the spliced form of $X b p-1$ in the proximal colon of Eeyore mice (Figure 10A). The ratio of spliced to unspliced $X b p-1$, which is used as a measure of UPR activation [35], increased 2.5- and 2.7-fold in Winnie and Eeyore proximal colon, respectively. Western blotting demonstrated increased GRP78 protein in both Winnie and Eeyore intestinal tissue (Figure 10B). In goblet cells from mutant mice GRP78 was detected immunohistochemically within the membranous accumulations, consistent with an association with misfolded Muc2, but notably not within thecae containing mucin packaged in granules for secretion (Figure 10C). Analysis of the Winnie and Eeyore intestinal transcriptome demonstrated increased transcription of the genes encoding the GRP78 and
GRP94 chaperones, the $\gamma$-subunit of the SEC61 pore through which misfolded proteins exit the ER, ubiquitin peptidases, and key elements of $\mathrm{Ca}^{2+}$ metabolism and signalling pathways consistent with disrupted $\mathrm{Ca}^{2+}$ sequestration ensuing from ER stress (see Table S2).

\section{Immunopathology in Mice with Muc2 Mutations}

Activation of the ER stress response represents a plausible mechanism for induction of inflammation, since it is known to activate $\mathrm{NF}-\kappa \mathrm{B}[36,37]$, and a diminished mucus barrier is likely to increase exposure to prokaryotic-associated molecular patterns that activate immunity and antigens. To examine local (epithelium and lamina propria) production of cytokines, we cultured explants from the distal colon and found Winnie and Eeyore mice secreted more of the inflammatory cytokines IL- $1 \beta$, TNF- $\alpha$, and IFN- $\gamma$ than did wild-type mice, but similar quantities of IL-13 (Figure 11A). In addition to the histological evidence of colitis, MLNs from mutant mice contained 5-fold more leukocytes than wild-type C57BL/ 6 mice (Figure 11B). Winnie and Eeyore MLN cells stimulated in vitro with PMA and ionomycin produced significantly more Th1 cytokines TNF- $\alpha$ and IFN- $\gamma$ (Figure 11C). Leukocytes from Winnie mice also produced the Th2 cytokine IL-13, known to be produced in UC (seven of nine cultures from Winnie mice produced IL-13 versus low levels in just one of 11 cultures from wild-type mice; Figure 11C). IL-1 $\beta$ was not produced by any MLN cultures. Analysis of the intestinal transcriptome revealed molecular antimicrobial and proinflammatory changes at $8 \mathrm{wk}$ of age, including: increased expression of SLPI, lipocalin-2, IL-1 $\beta$, IL-1 receptor antagonist, SOCS3, guanylate nucleotide binding protein 2, CD14, immunoglobulin chains and S100 macrophage activation markers, and decreased endothelin-2 (vascular modulator of inflammation) (see Figure S6; Tables S2 and S3).

The diminished mucus barrier, stressed epithelial cells, increased epithelial apoptosis, and increased production of inflammatory cytokines all could contribute to increased intestinal permeability in $M u c 2$ mutant mice. Therefore we assessed permeability using a FITC-dextran absorption assay 


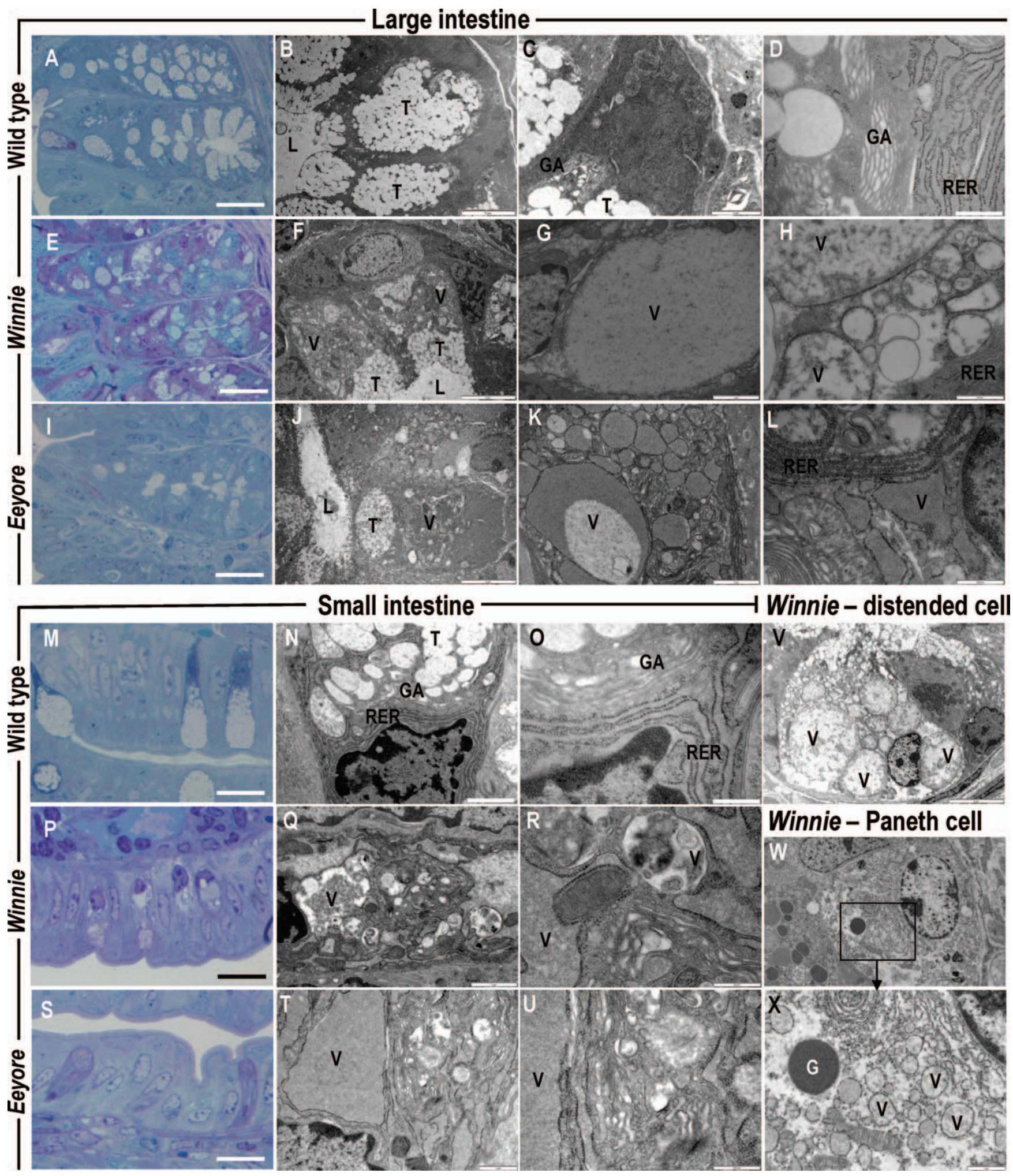

Figure 8. Ultrastructural Evidence of Endoplasmic Reticulum Stress in the Intestinal Epithelium of Mice with Muc2 Mutations

Semi-thin sections from resin embedded large intestine of wild-type (A), Winnie (E), and Eeyore (I) mice and small intestine of wild-type (M), Winnie (P), and Eeyore (S) mice stained with toluidine blue. Transmission electron micrographs from the large intestine $(\mathrm{B}-\mathrm{D}, \mathrm{F}-\mathrm{H}, \mathrm{J}-\mathrm{L}$, and $\mathrm{V})$ and small intestine ( $\mathrm{N}$, $\mathrm{O}, \mathrm{Q}, \mathrm{R}, \mathrm{T}, \mathrm{U}, \mathrm{W}$, and $\mathrm{X}$ ) of wild-type (B-D, N, and $\mathrm{O})$, Winnie ( $\mathrm{F}-\mathrm{H}, \mathrm{Q}, \mathrm{R}$, and V), and Eeyore (J-L, T, and U) mice. Note the reduced size of goblet cell thecae (indicated by a $T$ ) containing stored mucin granules and the presence of vacuoles (indicated by a $V$ ) surrounded by rough endoplasmic reticulum (RER) in Winnie and Eeyore. Other abbreviations: G, Paneth cell granule; GA, Golgi apparatus; L, lumen. Scale bars $40 \mu \mathrm{m}(\mathrm{A}, \mathrm{E}$, and I), $20 \mu \mathrm{m}(\mathrm{L}, \mathrm{O}$, and R), $5 \mu \mathrm{m}$ $(B, F, J$, and $U), 2 \mu \mathrm{m}(C, G, K, M, P, S$, and $V), 1 \mu \mathrm{m}(\mathrm{W}), 50 \mathrm{~nm}(\mathrm{D}, \mathrm{H}, \mathrm{L}, \mathrm{N}, \mathrm{Q}$, and $\mathrm{T})$. doi:10.1371/journal.pmed.0050054.g008 

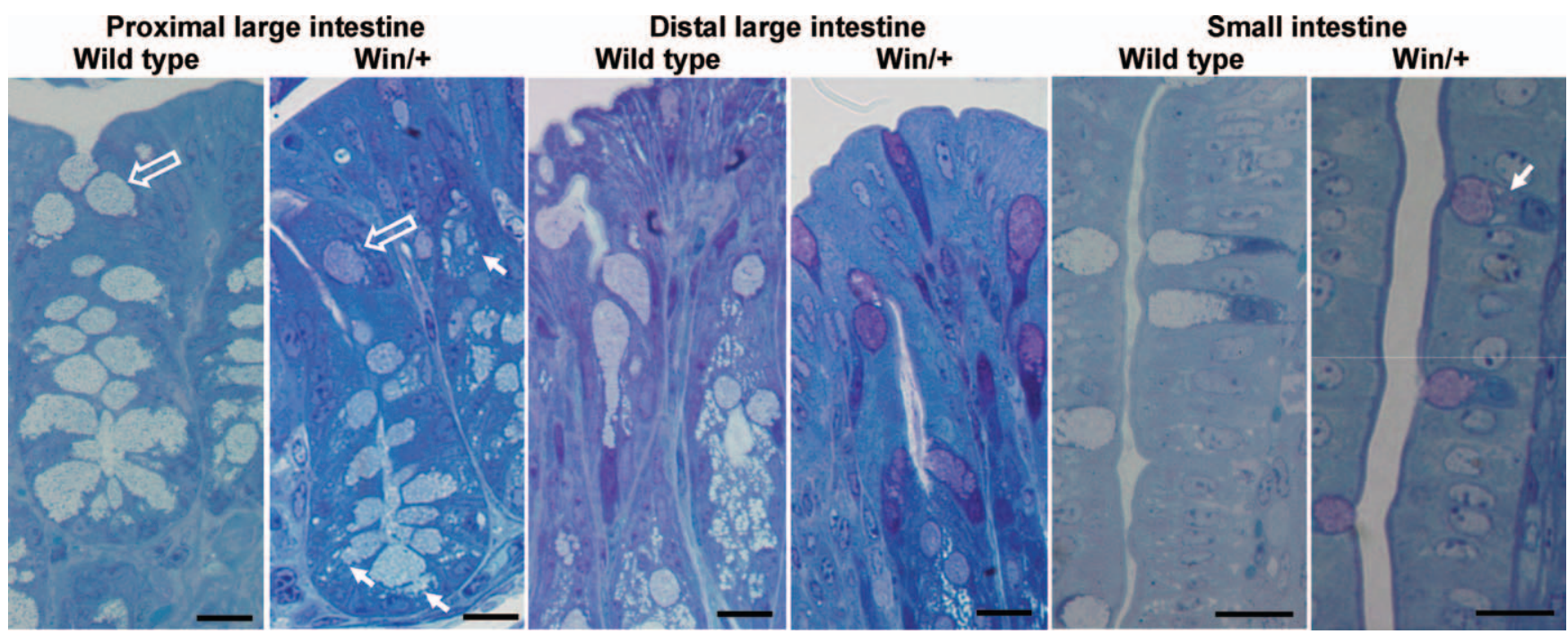

Figure 9. Evidence of Mucin Misfolding in Heterozygous Mice

Intestinal tissue from mice heterozygous for the Win mutation (Win/+) was fixed with glutaraldehyde, embedded in resin, and semi-thin sections stained with toluidine blue. Note the variable degree of vacuolisation of the goblet cells in the base of the crypts in the proximal large intestine (solid white arrows) and the lack of/minimal vacuolisation in surface goblet cells in the proximal large intestine (hollow arrows), distal large intestine and small intestinal villi. Tissue from wild-type C57BL6 mice is shown for comparison. Scale bars $=20 \mu \mathrm{m}$. doi:10.1371/journal.pmed.0050054.g009

and demonstrated a $96 \%$ increase in permeability in Winnie mice (Figure 11D). In IBD the luminal microbial bacteria are more frequently coated with immunoglobulin [24]. Using flow cytometry we demonstrated a 2.3-fold increase in the proportion of bacteria coated with immunoglobulin in Winnie mice (Figure 11E).

\section{MUC2 Precursor Accumulation and ER Stress in Human Ulcerative Colitis}

The intracellular accumulation of membranous vacuoles observed in the Muc2 mutant mice is reminiscent of the previously unexplained ultrastructural changes of human UC (but not Crohn's disease), which occur in both lesional and unaffected areas of intestine [38-42]. We hypothesized that these vacuoles could contain aberrantly assembled MUC2. Immunohistochemical detection of the MUC2 precursor with the $4 \mathrm{~F} 1$ antibody in human UC intestines demonstrated a pattern of staining consistent with accumulation of misfolded MUC2 in eight of ten patients (examples in Figure 12A). The MUC2 precursor was present throughout the cytoplasm of goblet cells, except in the theca (see arrows). Additionally, many cells lacking goblet cell morphology stained intensely, as described in previous studies with similar antibodies against the peptide core of the MUC2 O-glycosylated domain $[16,30,31]$. This observation contrasts with that in normal human intestinal goblet cells, in which staining was restricted to the perinuclear region where the ER is located. Alterations in mucin oligosaccharides are characteristic of UC [15,43], and in this light, previous studies of MUC2 precursor antibody staining have interpreted the increased staining as being a consequence of reduced size or density of O-linked oligosaccharides. However, using confocal microscopy we show that, both in normal colon and in UC colon, the 4F1 antibody does not react with either glycosylated mucin or secreted mucus (Figures 12B and S7), proving that the 4F1 staining represents accumulation of non-O-glycosylated precursor in UC. In normal colon $4 \mathrm{~F} 1$ reactivity is exclusively with the basal perinuclear, mostly subnuclear, region of the goblet cell, whereas in $\mathrm{UC} 4 \mathrm{~F} 1$ reactivity was often seen dispersed throughout the entire cytoplasm as would be predicted during ER stress. All UC samples with accumulation of the MUC2 precursor showed concomitant expression of GRP78, consistent with protein misfolding and ER stress, whereas GRP78 was not detected immunohistochemically in normal intestine (Figure 12A).

Using EM we found that intestinal goblet cell morphology in four UC patients with mild distal colitis showed similarities to that in Winnie and Eeyore mice, even in noninflamed areas of the colon, whereas four noninflamed controls showed no such changes (examples shown in Figure S8), as has been described previously [38-42]. Goblet cell density was reduced in UC, thecae were typically smaller, and vacuolar accumulations were present. EM showed dilated rough ER and often very large vacuoles surrounded by membranes lacking ribosomes, suggestive of accumulations in the Golgi apparatus, confirming the previous studies. Whilst non-UC intestinal goblet cell thecae contained densely packed mucin granules, UC goblet cell thecae often contained diffuse material of differing electron density dispersed between granules. The variable appearance of the granules in the UC thecae, which was not seen in Winnie and Eeyore, is consistent with either inappropriate mucin packaging in the Golgi or a greater proportion of nonmucin goblet cell secretions.

\section{Discussion}

This study demonstrates that the intestinal secreted mucin is prone to misfolding/aberrant assembly and that misfolding causes substantial ER stress, morphological goblet cell pathology, premature goblet cell apoptosis, and the development of chronic intestinal inflammation. We have described two strains of mice with ENU-induced allelic variants of $M u c 2$ and phenotypes that closely model human colitis. To our knowledge Winnie and Eeyore are the first animal models of 

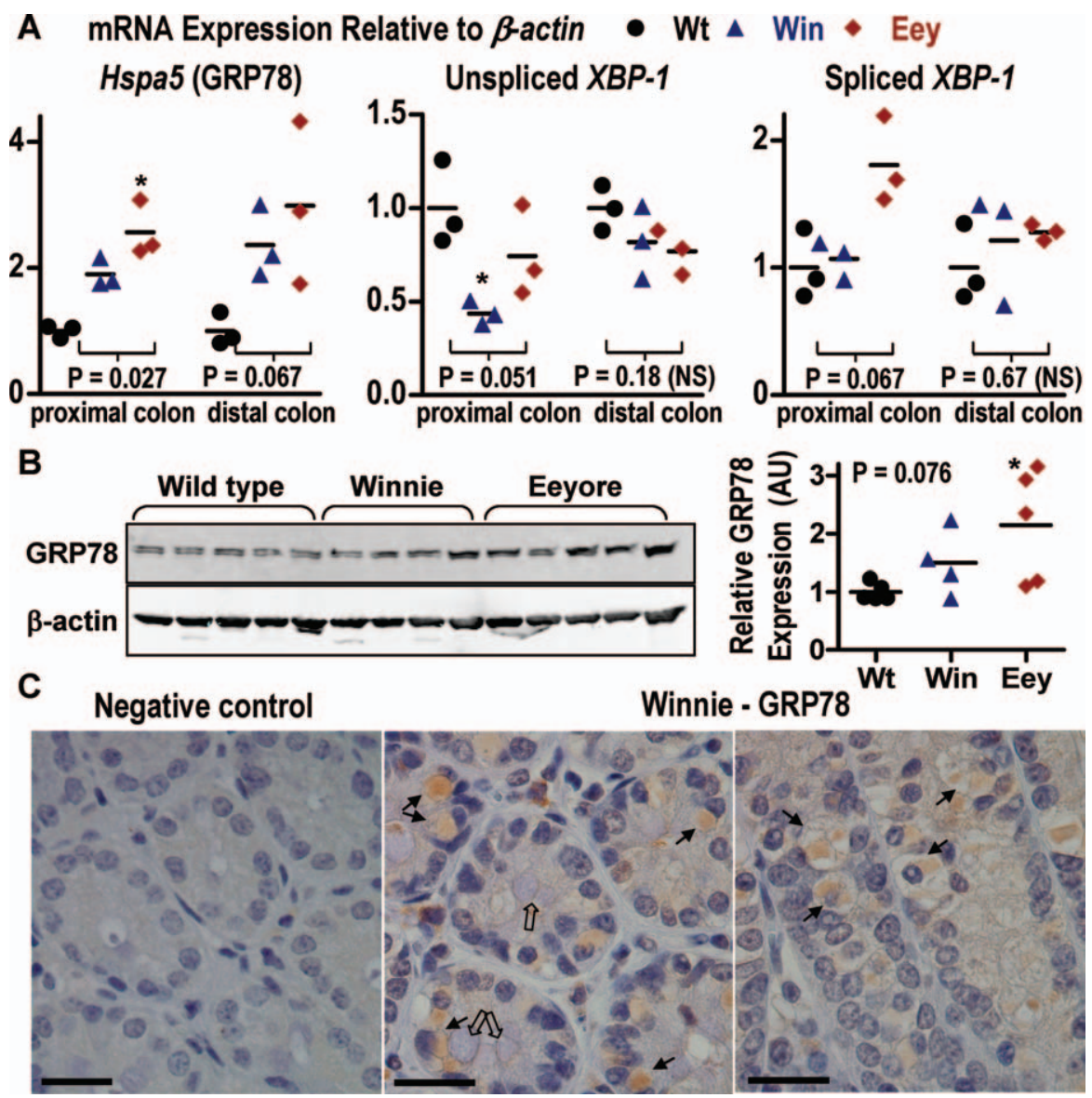

Figure 10. Evidence of ER Stress and UPR Activation in Mice with Muc2 Mutations

(A) mRNA expression of $h s p a 5$ (GRP78) and the unspliced and spliced forms of Xbp-1 in the proximal and distal colon of wild-type C57BL/6 (WT), Winnie (Win), and Eeyore (Eey) mice determined by quantitative PCR and expressed relative to $\beta$-actin with the mean ratio for the WT group in each tissue corrected to 1. Statistics: $n=3$ individual data points shown, Kruskal-Wallis nonparametric analysis ( $p$-values shown) with Dunn's multiple comparison test $\left({ }^{*} p<0.05\right.$ versus wild type). NS, not significant.

(B) Fluorescence Western blotting was used to determine the expression of GRP78 in the proximal colons of WT, Win, and Eey mice. Blots were simultaneously stained with antibodies reactive with $\beta$-actin as a loading control, and densitometry was used to quantify expression of each protein, which was then expressed as a proportion of the mean expression in wild-type mice with the mean ratio of the WT group corrected to 1 . Statistics as in (A), $n=5$.

(C) Transverse crypt section (centre) and a longitudinal crypt section through the vacuole-rich base of goblet cells (right) from Winnie mice showing immunohistochemical detection of GRP78 in vacuolar accumulations (solid arrows) but not in thecae where present (hollow arrows). Lack of staining in the absence of the GRP78 antibody demonstrates specificity (left, negative control). Scale bars $=50 \mu \mathrm{m}$ doi:10.1371/journal.pmed.0050054.g010

spontaneous intestinal inflammation arising due to single missense mutations in any gene. Their phenotype is characterized by diarrhoea, decreased goblet cell number, smaller goblet cell thecae, accumulation of Muc2 precursor in ER vacuoles within the goblet cell cytoplasm, increased epithelial cell proliferation and apoptosis, depletion of the secreted mucus layer, and spontaneous inflammation. The resulting pattern of inflammation with intestinal production of IL-1 $\beta$ and TNF- $\alpha$, and the production of both Th1 (TNF- $\alpha$ and IFN$\gamma)$ and Th2 (IL-13) cytokines by MLN leukocytes, resembles the complex and somewhat inconsistent patterns of cytokine production described in UC [44-52]. The IL-13 could be sourced from natural killer T cells, which have been shown to produce IL-13 in UC [50], and in oxazolone-induced colitis in mice, which is considered a UC-like model [53], or from natural killer cells, which are known to produce IL-13 in the intestine during some infections [54]. The increased intestinal permeability and increased coating of luminal bacteria with immunoglobulin also mirror the IBD phenotype [24,55].
The Winnie and Eeyore mutants provide new insights into the complex relationship between goblet cell physiology, mucin production, and intestinal inflammation. Several findings suggest that the phenotype is not accounted for simply by a reduction in the mucus layer. Both Win and Eey alleles cause biosynthetic defects leading to accumulation of Muc2 precursor, ER vacuolisation and stress, and activation of the UPR. Furthermore, despite an apparently normal mucus barrier, heterozygotes exhibited a restricted intestinal ER stress phenotype and an intermediate phenotype of sensitivity to luminal toxins, consistent with ER stress contributing to epithelial damage and environmentally induced inflammation. Finally, the presence of a large number of stressed cells within the intestinal epithelium and the production of IL-1 $\beta$, TNF- $\alpha$, and IL-13, are likely to attenuate epithelial tight junction integrity, leading to the impaired epithelial barrier function we demonstrate [52,56]. Direct biochemical links between ER stress and both local and systemic inflammation suggest that ER stress directly promotes inflammation [57,58], 

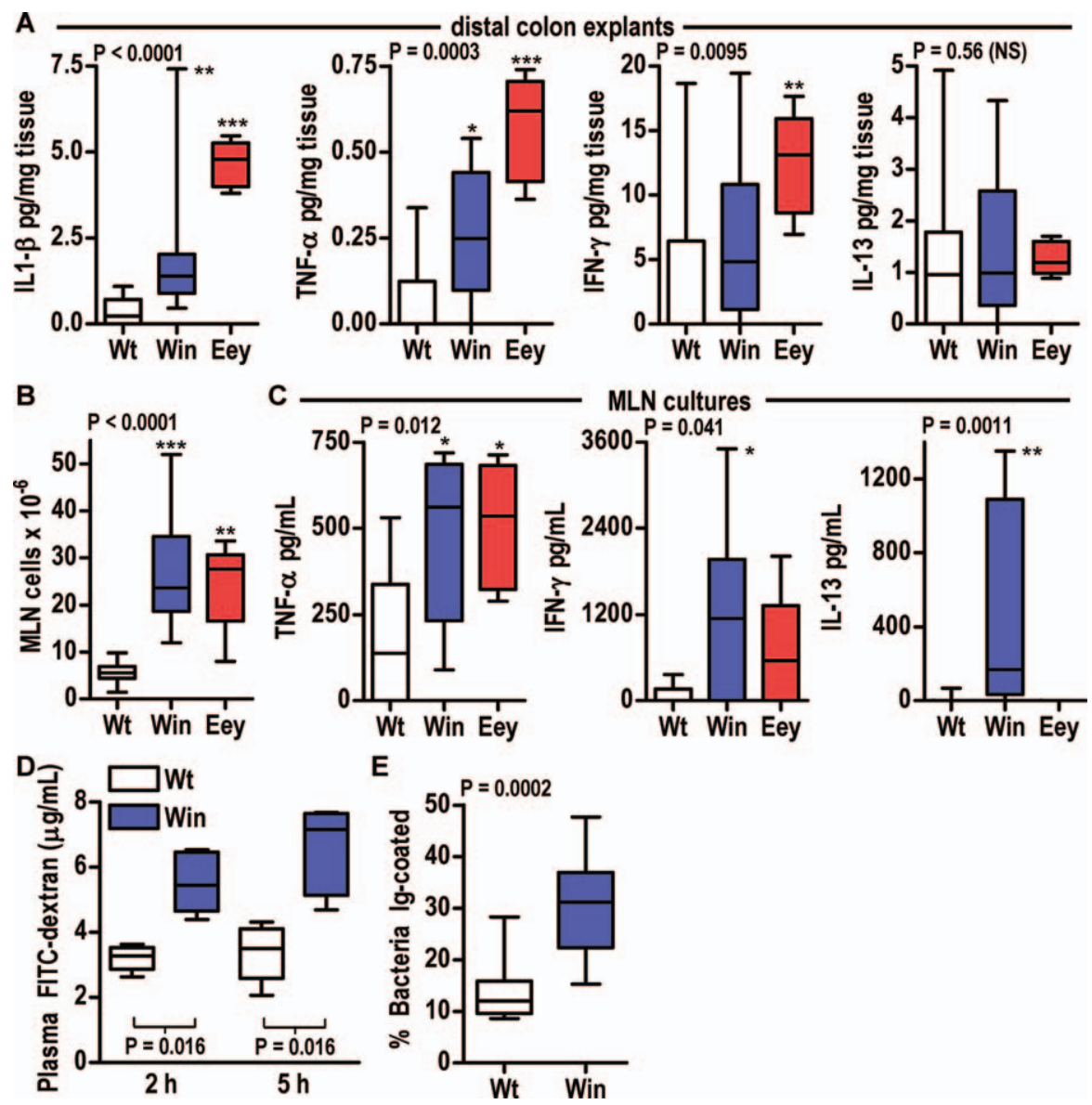

Figure 11. Immunopathology in Mice with Muc2 Mutations

(A) Concentrations of IL-1 $\beta$, TNF- $\alpha$, IFN- $\gamma$, and IL-13 in supernatants from distal colonic explants cultured for $24 \mathrm{~h}$ from WT $(n=14)$, Win $(n=12)$, and Eey $(n=5)$ mice at $12-18$ wk of age.

(B) The number of leukocytes in the MLNs was determined in C57BL/6 (WT, $n=16)$, Winnie (Win, $n=10)$, and Eeyore (Eey, $n=5)$ mice at 12 wk of age. (C) Concentrations of TNF- $\alpha$, IFN- $\gamma$, and IL-13 in supernatants from $2 \times 10^{6}$ MLN leukocytes stimulated with PMA and ionomycin and cultured for $48 \mathrm{~h}$, from WT $(n=11)$, Win $(n=9)$, and Eey $(n=5)$ mice at 12-18 wk of age. For cytokine analysis samples below the sensitivity of each assay were given values of 0 .

(D) Plasma FITC-dextran concentrations in WT and Win mice $(n=5) 2$ and $5 \mathrm{~h}$ following oral gavage.

(E) The proportion of bacteria coated with immunoglobulin determined by flow cytometry in faecal samples from WT $(n=10)$ and Win $(n=10)$ mice. Statistics: box plots show median, quartiles, and range; (A and C) Kruskal-Wallis nonparametric analysis ( $p$-values shown) with Dunn's multiple comparison test $\left({ }^{*} p<0.05,{ }^{* *} p<0.01,{ }^{* * *} p<0.001\right.$ versus WT); NS, not significant; (B, D, and E) Mann-Whitney U-test, $p$-values shown. doi:10.1371/journal.pmed.0050054.g011

including inducing activation of $\mathrm{NF}-\kappa \mathrm{B}$ via multiple pathways within cells experiencing ER stress [36,37,59,60]. NF- $\mathrm{BB}$ activation is considered central to intestinal inflammation $[61,62]$ and has been observed in unaffected tissues from patients with UC and in asymptomatic identical twins [63]. During intestinal ER stress it is likely that NF- $\mathrm{KB}$ activation occurs in epithelial cells both as a direct result of ER stress and due to increased exposure to microbial Toll-like receptor ligands as a result of a diminished mucus barrier and increased epithelial permeability.

While ER stress provides one contributory pathway to intestinal pathology, it is inherently coupled with a reduction in quantity and quality of the mucus layer. The mutant strains contain fewer goblet cells due to apoptosis, less Muc2 is likely to be secreted per goblet cell due to misfolding and the UPRinitiated translational block, and the mucin that is secreted could be incorrectly oligomerised and affect the rheological properties of mucus. The relative importance of ER stress and changes to the mucus barrier cannot be easily distinguished, because they are inextricably linked and may well act in concert. However, several lines of evidence suggest that Muc2 depletion in the absence of ER stress is not sufficient to cause colitis. First, even in $M u c 2^{-l-}$ mice the colitis phenotype appears to arise only on a permissive genetic background $[21,22]$. Second, specific depletion of approximately $60 \%$ of goblet cells in mITF/DT-A transgenic mice did not trigger spontaneous inflammation and reduced susceptibility to DSSinduced colonic injury [23]. Third, Gfi $1^{-l-}$ mice, which produce very few intestinal secretory lineage cells, including goblet cells, do not show intestinal inflammation [64]. There are substantial phenotypic differences between the Muc2 mutants and $\mathrm{Muc}^{-1-}$ mice. Although $\mathrm{Muc} 2^{-1-}$ mice lack goblet cell thecae, they maintain normal goblet cell numbers and production of other secretions [21]. Muc2 $2^{-l-}$ show neoexpression in the colon of the Muc6 gastric mucin [22], whereas, similar to UC [65], Muc6 was not expressed by Winnie and Eeyore. Muc2 deficiency causes increased mitosis/crypt hyperproliferation [21] and, on a $129 / \mathrm{Sv}$ background but not a C57BL/6J $\times 129 / \mathrm{Sv}$ background, growth retardation, diarrhoea, occasional rectal prolapses, focal erosions, and 
A

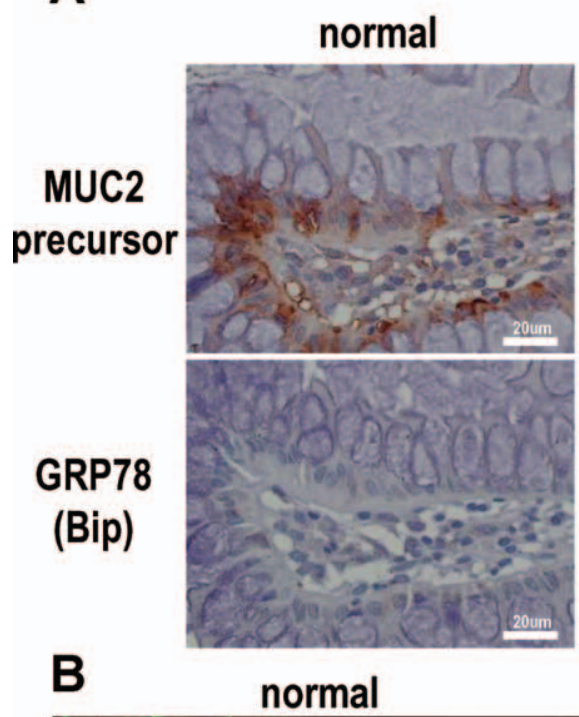

ulcerative colitis case 1
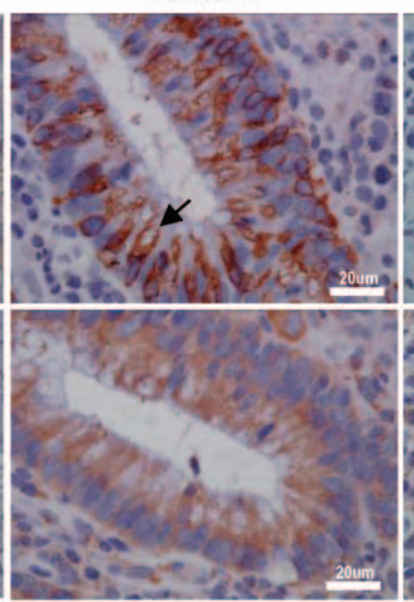

ulcerative colitis case 2

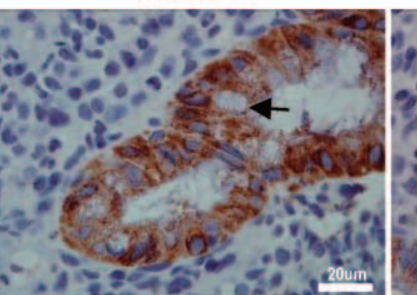

ulcerative colitis case 3

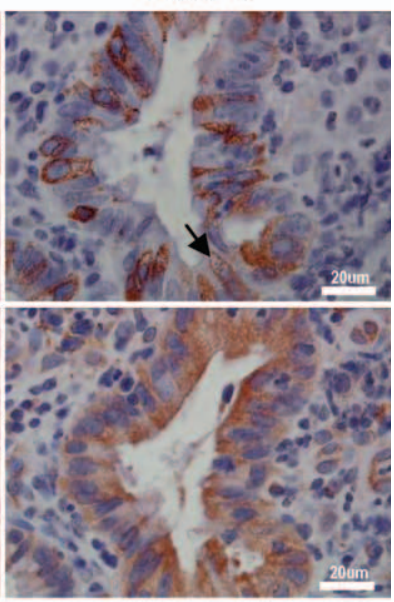

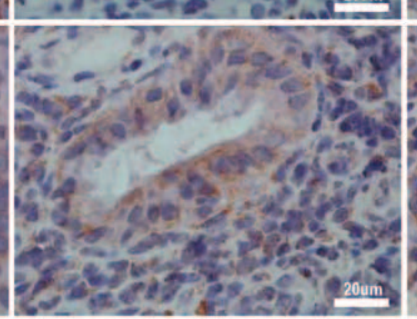

\section{ulcerative colitis}

ulcerative colitis

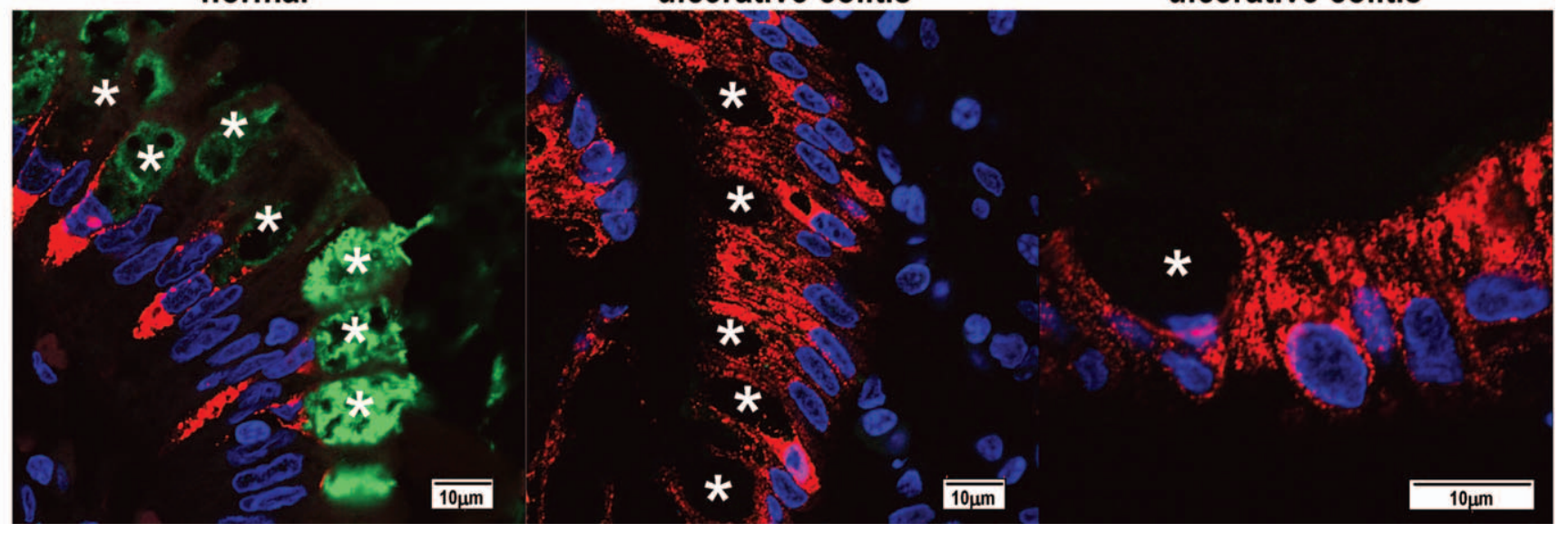

Figure 12. Evidence for MUC2 Precursor Accumulation and ER Stress in Human UC

(A) The MUC2 precursor and GRP78 were detected immunohistochemically. One normal colonic biopsy and three representative cases of UC of ten examined are shown. Note the MUC2 precursor antibody does not react with goblet cell thecae, where present (arrows).

(B) Confocal microscopy of goblet cells from the colon of an unaffected individual and two UC patients showing accumulation of the MUC2 precursor identified with antibody 4F1 (red) throughout the cytoplasm in UC goblet cells, many of which lack thecae, but not in normal colon. Note that 4F1 does not react with goblet cell thecae (identified by *) in normal or UC colon, demonstrating it cannot react with O-glycosylated MUC2 that has exited the Golgi apparatus. Note that some goblet cell thecae contain MUC2 with O-linked sugars identified with the DBA lectin (green) but that UC goblet cells are mostly DBA lectin-negative. Nuclei are stained with DAPI (blue). Single colour images of these composites are provided in Figure S7.

Scale bars $=20 \mu \mathrm{m}(\mathrm{A})$ and $10 \mu \mathrm{m}(\mathrm{B})$.

doi:10.1371/journal.pmed.0050054.g012

mild inflammation in the distal colon and increased susceptibility to DSS-induced colitis [22]. However, an increase in epithelial apoptosis occurs in Winnie and Eeyore mice and in humans with UC, whereas in contrast complete loss of Muc2 reduces apoptosis [21]. Even if one argues that the dominant feature causing colitis in Winnie and Eeyore is the depletion of the mucus barrier, then these two spontaneously occurring models demonstrate how mucin depletion sufficient to initiate colitis can occur via simple missense mutations in $M u c 2$, and that heterozygosity for such mutations is sufficient to cause enhanced susceptibility to environmental insults.

Previous evidence also supports a role for ER stress in intestinal inflammation. Mice lacking IRE1 $\beta$, a key initiator of the UPR, are more susceptible to DSS-induced colitis [66]. Furthermore, ER stress proteins are up-regulated in DSSinduced colitis in mice and in UC in humans [57], and GRP78 expression is up-regulated in ex vivo-cultured intestinal epithelial cells from patients with colitis [59]. Ultrastructural studies in UC and Crohn's disease [38-42,67], together with data reported here of both inflamed and noninflamed UC colon, report cellular changes in UC but not Crohn's disease consistent with protein misfolding and ER and/or Golgi apparatus stress, similar to those seen in Winnie and Eeyore mice. In addition we report ultrastructural changes in goblet cell thecae in UC suggestive of either inappropriate granule formation or premature dissolution of stored granules prior to secretion. Importantly, the presence of aberrant goblet cell morphology in unaffected proximal colon of UC patients, as reported here and previously [38], suggests that this defect precedes rather than follows inflammation. Furthermore, previous immunohistochemical studies with VNTR peptide core-reactive MUC2 antibodies [16,30,31] reported diffuse staining in UC goblet cells and, to a lesser extent, in colonic 


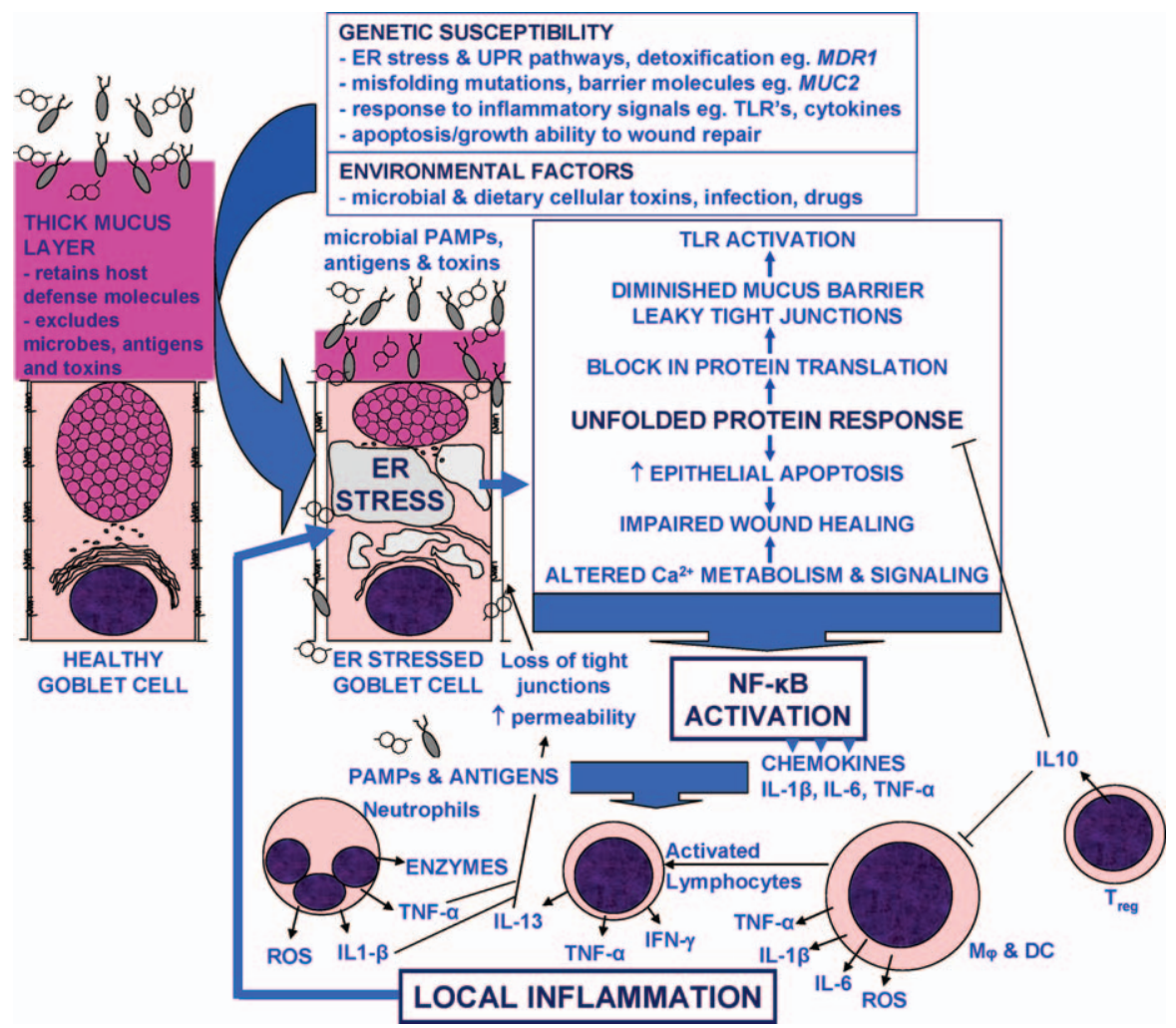

Figure 13. A Model for ER Stress in the Pathophysiology of Intestinal Inflammation

This model recognizes that genetic and environmental factors can combine to invoke ER stress, reduced mucus production, and inflammation. Local inflammation can then exacerbate ER stress, potentially establishing a chronic cycle of inflammation in susceptible individuals. Abbreviations: ER, endoplasmic reticulum; $M \varphi$, macrophage; MDR1, multi-drug resistance gene 1; PAMP, prokaryocyte-associated molecular pattern; ROS, reactive oxygen species; TLR, toll-like receptor; UPR, unfolded protein response. doi:10.1371/journal.pmed.0050054.g013

Crohn's disease, that is independent of the degree of inflammation [16]. We have replicated this finding and demonstrate that, rather than this staining pattern reflecting glycosylation changes in mature MUC2, it is the precursor that accumulates in a similar pattern to that seen in Winnie and Eeyore. We also show concomitant expression of GRP78, providing biochemical evidence of ER stress.

The size and complexity of Muc2 are likely to render it particularly susceptible to aberrations in folding and assembly of the oligomeric complex. Hyperoligomerisation of the recombinant Winnie D3 domain caused retention in the secretory pathway, which is consistent with altered Muc2 homo-oligomerisation being the cause of ER retention in vivo. Even though $\mathrm{N}$-terminal oligomerisation of Muc2 is thought to occur in the Golgi, the presence of ribosomes in vacuole membranes and the lack of O-glycans on the accumulated precursor show that aberrant oligomerisation with the Win mutation occurs in the ER. The complex nature of misfolded oligomerised Muc2 is likely to present a major challenge to the ER machinery responsible for denaturing and removing misfolded proteins from the ER for degradation $[33,68]$. The more severe ER stress in the goblet cells deep in the crypts of the proximal large intestine is consistent with the longer lifespan (15-21 d) of these cells compared with the surface goblet cells in the proximal colon and goblet cells in the distal colon and small intestine $(4-5 \mathrm{~d})$ [32]. Thus the extended lifespan of goblet cells following mucosal damage could unmask genetic susceptibilities to ER stress and amplify the effects of environmental ER stressors.

Based on evidence from Winnie and Eeyore, single nucleotide polymorphisms (SNPs) in oligomerisation domainencoding exons of MUC2 may identify individuals predisposed to intestinal disease. The D-domains of MUC2 share very high homology with the blood clotting glycoprotein von Willebrand Factor (vWF) which also forms homo-oligomers. Autosomal dominant and recessive mutations in all four Ddomains of vWF cause von Willebrand disease [69], typically via altered homo-oligomerisation, and are therefore analogous to the Win and Eey Muc2 mutations. A single genomewide scan has identified an IBD susceptibility locus at Chromosome $11 \mathrm{p}$, which contains $M U C 2$ within a cluster of four mucin genes at $11 \mathrm{p} 15.5$ [70]. A study of $M U C 2$ polymorphisms found no association with UC, but examined only tandem repeat length polymorphisms incapable of distinguishing underlying SNPs [71]. Interestingly, a study examining a single MUC2 D1 oligomerisation domain polymorphism found an association with Crohn's disease but not UC [72]. There are at least 30 nonsynonomous SNPs in the exons encoding MUC2 oligomerisation domains, warranting comprehensive studies in IBD focused on these MUC2 exons.

Although MUC2 is the most likely candidate for misfolding mutations, mutations in genes encoding any proteins with a predilection for misfolding, as well as in the genes encoding ER chaperones, elements of the UPR, and/or detoxification proteins (e.g., MDR1) could trigger the ER stress pathway to 
colitis. The resultant UPR could lead to a translational block decreasing MUC2 synthesis, and the ER stress could cause MUC2 misfolding, even in the absence of mutations in MUC2, duplicating the ER stress/reduced mucus barrier phenotype. Similarly, inappropriate responses to the normal level of misfolding occurring in secretory cells could trigger the ER stress pathway to intestinal inflammation. Highlighting likely interindividual differences in the response to misfolded proteins, it was recently shown that the class of genes with the highest level of inherited variation in expression were genes involved in the UPR [73].

Thus, a complex genetic basis for UC but involving the same pathway revealed by single alleles with strong effects (such as Win and Eey) is plausible. Furthermore, this mechanism could account for a complex interaction with environmental triggers. Candidate triggers include intestinal viruses, bacteria, dietary toxins, reactive oxygen species, and bile salts, which can directly cause or exacerbate ER stress. Furthermore, local inflammation itself can also enhance ER stress via the actions of reactive oxygen species and TNF- $\alpha$ [74], demonstrating how a chronic cycle of ER stress, mucus depletion, and inflammation could arise. Conversely, some local factors may ameliorate the consequences of ER stress; for example, IL-10 has recently been shown to modulate the UPR in intestinal cells by inhibiting nuclear translocation of the ATF6 transcription factor [59]. Changes in production of other goblet cell molecules involved in barrier function and/ or activation of immunity during goblet cell ER stress could also have important impacts. For example, the gene encoding RELM- $\beta$ which has been reported to have both pro- and antiinflammatory activities [75,76], shows altered expression in Winnie and Eeyore (Table S3). Thus the severity of ER stress, the nature of the UPR, and the degree of inflammation in response to intestinal ER stress are likely to be dependent on a range of other genetic factors, consistent with the multiallelic nature of IBD.

\section{Limitations of This Study}

Although the study shows that mice with aberrant mucin assembly and ER stress develop inflammation similar to human UC, the cellular and molecular pathways leading to inflammation remain to be fully characterized. There are also differences in the physiology of the intestine in the mouse, including the distribution and lifespan of goblet cells, that could influence translation of our findings to human physiology. Our study confirms previous studies showing signs of ER stress in UC but does not ascertain the genetic or environmental drivers of ER stress in UC, relate the ER stress to differing clinical phenotypes, nor explore the effects of treatment. Comprehensive, appropriately powered studies combining genetics, clinical pathology (including biochemical and ultrastructural assessment of ER stress), and environmental epidemiology are required to address the involvement of ER stress in human IBD.

\section{Conclusions}

The evidence is consistent with a model of UC pathogenesis (Figure 13) in which ER stress due to genetic susceptibility and/or environmental factors results in MUC2 precursor accumulation and decreased production of glycosylated MUC2 by individual goblet cells leading to smaller/loss of goblet cell thecae, a reduced lifespan of individual goblet cells, and a decreased total MUC2 production. In this scenario a diminished mucus barrier would lead to greater toxin and antigen exposure, driving further ER stress, with both the depleted mucus barrier and ER stress triggering local mucosal inflammation. Local inflammatory cytokines could increase epithelial permeability and directly exacerbate ER stress through reactive oxygen species production, leading to an unresolving cycle of epithelial damage and inflammation. In this model of colitis, goblet cell ER stress and a diminished mucus barrier are intrinsically linked concurrent events, irrespective of whether the trigger is a genetic lesion predisposing to misfolding, a lesion resulting in an inappropriate UPR, or an environmental insult.

\section{Supporting Information}

Figure S1. Heat Map Showing Relative Expression of Genes Altered in both Muc2 Mutant Mouse Strains

Hierarchical clustering of 414 probe sets that were considered upregulated or down-regulated in intestinal RNA in at least 2/3 Eeyore and 2/3 Winnie mice compared to expression in at least 2/3 C57BL/6 wild-type mice. Heat map was generated using dChip2006, with each probe set represented as normalized signal minus mean divided by standard deviation using Euclidean distance metric and average linkage method. Row names are concatenated Affymetrix Mouse $430 \_2$ probe ID and the Unigene symbol. The entire microarray data set can be accessed at NCBI GEO accession no. GSE9913 (http:/l www.ncbi.nlm.nih.gov/geo/).

Found at doi:10.1371/journal.pmed.0050054.sg001 (312 KB PDF).

Figure S2. Colon Length in Wild-Type and Winnie Mice at 6 and 12 Weeks of Age

Statistics: box plots show median, quartiles, and range; $n=5-6$; no statistical difference by Kruskal-Wallis nonparametric analysis.

Found at doi:10.1371/journal.pmed.0050054.sg002 (100 KB PDF).

Figure S3. Susceptibility of Winnie and Eeyore Mice to Dextran Sodium Sulphate-Induced Colitis-Histological Examples of Colitis

(A) Wild-type C57BL/6 (WT), Winnie (Win), and Eeyore (Eey) mice were given $2 \%$ DSS in drinking water or water alone for $7 \mathrm{~d}$. Representative examples of histology showing colitis on days 3 and 7 , and small intestinal pathology on day 7 , are shown. Scale bars $=100 \mu \mathrm{m}$.

(B) Wild-type C57BL/6 and Winnie mice were given $3 \%$ DSS in drinking water or drinking water alone $(\mathrm{CON})$ for $7 \mathrm{~d}$; representative examples of histological colitis are shown. Scale bars $=300 \mu \mathrm{m}$.

(C) Representative examples of ulcerating colitis in Winnie mice given $0.5 \%$ DSS for $4 \mathrm{wk}$.

Found at doi:10.1371/journal.pmed.0050054.sg003 (2.6 MB PDF).

Figure S4. Susceptibility of Winnie and Eeyore Mice to Dextran Sodium Sulphate-Induced Colitis-Additional Clinical, Biochemical, and Haematological Data

Wild-type C57BL/6, Winnie, and Winnie heterozygous (Win/+) mice were given $3 \%$ DSS in drinking water or drinking water alone (CON) for $7 \mathrm{~d}$, at which time serum amyloid protein, serum triglycerides, and blood monocyte levels and haemoglobin concentrations were assessed. Rectal bleeding and stool scores were assessed daily. Statistics: box plots show median, quartiles, and range; $n=5 ; p$ values for Kruskal-Wallis nonparametric analysis comparing DSStreated WT, Winlt, and Win mice are shown, Dunn's multiple comparison test versus WT $* p<0.05, * * p<0.01$.

Found at doi:10.1371/journal.pmed.0050054.sg004 (117 KB PDF).

Figure S5. Demonstration of Muc2 Precursor Accumulation in Muc2 Mutant Mice by Confocal Microscopy

(A-C) Individual colour confocal images of the composite confocal images shown in Figure 6C.

(D) Staining of proximal colon in an Eeyore mouse.

(E) Negative control sections; note no background staining is seen with omission of the Muc2 antibody or DBA lectin (negative control). Staining as indicated, scale bars $=10 \mu \mathrm{m}$.

Found at doi:10.1371/journal.pmed.0050054.sg005 (4.6 MB PDF). 
Figure S6. Relative Expression of Genes Classified by Ontology into Those Encoding Cytokines and Cytokine Receptors, Chemokines and Chemokine Receptors, Interferons and Interferon-Inducible Proteins, and Leukocyte-Signalling Proteins in Winnie Compared to C57BL/6 Wild-Type Mice

The signal intensity for each related probe_ID was averaged within the Winnie and wild-type mice cohorts $(n=3)$ and graphed on a $\log 10$ scale. The grey line represents the 1:1 signal intensity intersection. Each spot has been coded: red for $>2$ Winnie:wild type, green for $<0.5$ Winnie:wild type, and grey for all values $>0.5$ and $<2.0$. The entire microarray dataset can be accessed at NCBI GEO Accession No. GSE9913 (http:// www.ncbi.nlm.nih.gov/geo/).

Found at doi:10.1371/journal.pmed.0050054.sg006 (57 KB PDF).

Figure S7. Evidence of MUC2 Precursor Accumulation in Ulcerative Colitis

Individual confocal images of the composite confocal images shown in Figure 12B. Staining with the MUC2 precursor antibody 4F1, DBA lectin, and DAPI as indicated. Scale bars $=10 \mu \mathrm{m}$.

Found at doi:10.1371/journal.pmed.0050054.sg007 (560 KB PDF).

Figure S8. Morphological Evidence of ER Stress in Ulcerative Colitis

Intestinal biopsies from two healthy individuals, the unaffected proximal colon of three UC patients, and the affected distal colon of one of those UC patients, were examined by light (left) and electron (right) microscopy. Arrows indicate the presence of vacuoles in goblet cells. Abbreviations: NG, nongranular material; RER, rough endoplasmic reticulum; T, theca/mucin granules; V, vacuole. Scale bars are individually annotated.

Found at doi:10.1371/journal.pmed.0050054.sg008 (2.9 MB PDF).

Table S1. Histological Scoring of Murine Colitis

Found at doi:10.1371/journal.pmed.0050054.st001 (67 KB DOC).

Table S2. Comparison of the Intestinal Transcriptome of C57BL/6, Winnie and Eeyore Mice-Genes Involved in ER Stress, Antimicrobial Defence, Wound Repair, Epithelial Growth, Cell Cycle, and Apoptosis

Found at doi:10.1371/journal.pmed.0050054.st002 (61 KB DOC).

Table S3. Comparison of the Intestinal Transcriptome of C57BL/6, Winnie and Eeyore Mice-Genes Involved in Inflammation, Metabolism, Detoxification, and the Mucus Barrier

Found at doi:10.1371/journal.pmed.0050054.st003 (60 KB DOC).

\section{Acknowledgments}

We thank R. Lourie for pathological interpretation and advice, G. Toukatly and D. Roche for laboratory technical assistance, A. Burns for animal care, and $\mathrm{H}$. Wu for assistance with mapping the mutations.

Author contributions. CKH, MCC, RE, GRP, SBT, DT, DJT, CWP, TLC, RA, MK, KAN, NAH, and MAM planned and conducted experiments, analysed data, and contributed to preparation of the manuscript. RJC, THJF, and CCG were involved in experimental planning, data analysis and preparation of the manuscript.

Funding: Funding support was from the Australian NHMRC (235608) and the Broad Medical Research Program (0032). CKH is supported by ANZ Postgraduate Scholarship, RE by a University of Queensland Reginald Ferguson Fellowship, THJF by an NHMRC Clinical Practitioner Fellowship, and MAM by a Cancer Council of Queensland Senior Research Fellowship. The funders had no role in study design, data collection and analysis, decision to publish, or preparation of the manuscript.

\section{References}

1. Herrmann A, Davies JR, Lindell G, Martensson S, Packer NH, et al. (1999) Studies on the "insoluble" glycoprotein complex from human colon. Identification of reduction-insensitive MUC2 oligomers and C-terminal cleavage. J Biol Chem 274: 15828-15836.

2. Lidell ME, Johansson ME, Morgelin M, Asker N, Gum JR, et al. (2003) The recombinant C-terminus of the human MUC2 mucin forms dimers in Chinese-hamster ovary cells and heterodimers with full-length MUC2 in LS $174 \mathrm{~T}$ cells. Biochem J 372: 335-345.

3. Godl K, Johansson ME, Lidell ME, Morgelin M, Karlsson H, et al. (2002) The $\mathrm{N}$ terminus of the MUC2 mucin forms trimers that are held together within a trypsin-resistant core fragment. J Biol Chem 277: 47248-47256.
4. Asker N, Axelsson MAB, Olofsson SO, Hansson GC (1998) Dimerization of the human MUC2 mucin in the endoplasmic reticulum is followed by a Nglycosylation-dependent transfer of the mono- and dimers to the Golgi apparatus. J Biol Chem 273: 18857-18863.

5. Sheehan JK, Thornton DJ, Howard M, Carlstedt I, Corfield AP, et al. (1996) Biosynthesis of the MUC2 mucin-evidence for a slow assembly of fully glycosylated units. Biochem J 315: 1055-1060.

6. Gasche C, Alizadeh B, Pena A (2003) Genotype-phenotype correlations: how many disorders constitute inflammatory bowel disease? Eur J Gastroenterol Hepatol 15: 599-606.

7. Silverberg M, Satsangi J, Ahmad T, Arnott I, Bernstein C, et al. (2005) Toward an integrated clinical, molecular and serological classification of inflammatory bowel disease: Report of a Working Party of the 2005 Montreal World Congress of Gastroenterology. Can J Gastroenterol 19: 5-36.

8. Gasche C, Scholmerich J, Brynskov J, D'Haens G, Hanauer S, et al. (2000) A simple classification of Crohn's disease: report of the Working Party for the World Congresses of Gastroenterology, Vienna 1998. Inflamm Bowel Dis 6: $8-15$.

9. Sartor RB (2006) Mechanisms of disease: pathogenesis of Crohn's disease and ulcerative colitis. Nat Clin Pract Gastroenterol Hepatol 3: 390-407.

10. Xavier RJ, Podolsky DK (2007) Unravelling the pathogenesis of inflammatory bowel disease. Nature 448: 427-434.

11. Dvorak AM, Osage JE, Monahan RA, Dickersin GR (1980) Crohn's disease: transmission electron microscopic studies. III. Target tissues. Proliferation of and injury to smooth muscle and the autonomic nervous system. Hum Pathol 11: 620-634.

12. Trabucchi E, Mukenge S, Baratti C, Colombo R, Fregoni F, et al. (1986) Differential diagnosis of Crohn's disease of the colon from ulcerative colitis: ultrastructure study with the scanning electron microscope. Int J Tissue React 8: 79-84.

13. Tytgat KMAJ, van der Wal JWG, Einerhand AWC, Buller HA, Dekker J (1996) Quantitative analysis of MUC2 synthesis in ulcerative colitis. Biochem Biophys Res Commun 224: 397-405.

14. Van Klinken BJW, van der Wal JWG, Einerhand AWC, Buller HA, Dekker J (1999) Sulphation and secretion of the predominant secretory human colonic mucin MUC2 in ulcerative colitis. Gut 44: 387-393.

15. Corfield AP, Myerscough N, Bradfield N, Corfield CDA, Gough M, et al. (1996) Colonic mucins in ulcerative colitis: evidence for loss of sulfation. Glycoconj J 13: 809-822.

16. Hanski C, Born M, Foss HD, Marowski B, Mansmann U, et al. (1999) Defective post-transcriptional processing of MUC2 mucin in ulcerative colitis and in Crohn's disease increases detectability of the MUC2 protein core. J Pathol 188: 304-311.

17. Jass JR, Walsh MD (2001) Altered mucin expression in the gastrointestinal tract: a review. J Cell Mol Med 5: 327-351.

18. Podolsky DK, Isselbacher KJ (1983) Composition of human colonic mucin. Selective alteration in inflammatory bowel disease. J Clin Invest 72: 142 153.

19. Tysk C, Riedesel H, Lindberg E, Panzini B, Podolsky D, et al. (1991) Colonic glycoproteins in monozygotic twins with inflammatory bowel disease. Gastroenterology 100: 419-423.

20. An G, Wei B, Xia B, McDaniel JM, Ju T, et al. (2007) Increased susceptibility to colitis and colorectal tumors in mice lacking core 3-derived O-glycans. J Exp Med 204: 1417-1429.

21. Velcich A, Yang W, Heyer J, Fragale A, Nicholas C, et al. (2002) Colorectal cancer in mice genetically deficient in the mucin Muc2. Science 295: 17261729 .

22. Van der Sluis M, De Koning BA, De Bruijn AC, Velcich A, Meijerink JP, et al. (2006) Muc2-deficient mice spontaneously develop colitis, indicating that MUC2 is critical for colonic protection. Gastroenterology 131: 117-129.

23. Itoh H, Beck PL, Inoue N, Xavier R, Podolsky DK (1999) A paradoxical reduction in susceptibility to colonic injury upon targeted transgenic ablation of goblet cells. J Clin Invest 104: 1539-1547.

24. van der Waaij LA, Kroese FG, Visser A, Nelis GF, Westerveld BD, et al. (2004) Immunoglobulin coating of faecal bacteria in inflammatory bowel disease. Eur J Gastroenterol Hepatol 16: 669-674.

25. Devine PL, McGuckin MA, Birrell GW, Whitehead RH, Sachdev GP, et al. (1993) Monoclonal antibodies reacting with the MUC2 mucin core protein. Br J Cancer 67: 1182-1188.

26. Carlstedt I, Herrmann A, Hovenberg H, Lindell G, Nordman H, et al. (1995) "Soluble" and "insoluble" mucins-identification of distinct populations. Biochem Soc Trans 23: 845-851.

27. Thornton DJ, Khan N, Sheehan JK (2000) Separation and identification of mucins and their glycoforms. Methods Mol Biol 125: 77-85.

28. McGuckin MA, Thornton DJ (2000) Detection and quantitation of mucins using chemical, lectin, and antibody methods. Methods Mol Biol 125: 45-55.

29. Hong MY, Turner ND, Carroll RJ, Chapkin RS, Lupton JR (2005) Differential response to DNA damage may explain different cancer susceptibility between small and large intestine. Exp Biol Med (Maywood) 230: 464-471.

30. Hinoda Y, Akashi H, Suwa T, Itoh F, Adachi M, et al. (1998) Immunohistochemical detection of MUC2 mucin core protein in ulcerative colitis. J Clin Lab Anal 12: 150-153.

31. Shaoul R, Okada Y, Cutz E, Marcon MA (2004) Colonic expression of 
MUC2, MUC5AC, and TFF1 in inflammatory bowel disease in children. J Pediatr Gastroenterol Nutr 38: 488-493.

32. Altmann GG (1983) Morphological observations on mucus-secreting nongoblet cells in the deep crypts of the rat ascending colon. Am J Anat 167: 95-117.

33. Marciniak SJ, Ron D (2006) Endoplasmic reticulum stress signaling in disease. Physiol Rev 86: 1133-1149.

34. Ron D, Walter P (2007) Signal integration in the endoplasmic reticulum unfolded protein response. Nat Rev Mol Cell Biol 8: 519-529.

35. Marciniak SJ, Yun CY, Oyadomari S, Novoa I, Zhang Y, et al. (2004) CHOP induces death by promoting protein synthesis and oxidation in the stressed endoplasmic reticulum. Genes Dev 18: 3066-3077.

36. Hu P, Han Z, Couvillon AD, Kaufman RJ, Exton JH (2006) Autocrine tumor necrosis factor alpha links endoplasmic reticulum stress to the membrane death receptor pathway through IRE1alpha-mediated NF-kappaB activation and down-regulation of TRAF2 expression. Mol Cell Biol 26: 30713084 .

37. Deng J, Lu PD, Zhang Y, Scheuner D, Kaufman RJ, et al. (2004) Translational repression mediates activation of nuclear factor kappa B by phosphorylated translation initiation factor 2. Mol Cell Biol 24: 1016110168.

38. Delpre G, Avidor I, Steinherz R, Kadish U, Ben-Bassat M (1989) Ultrastructural abnormalities in endoscopically and histologically normal and involved colon in ulcerative colitis. Am J Gastroenterol 84: 1038-1046.

39. Gonzalez-Licea A, Yardley JH (1966) Nature of the tissue reaction in ulcerative colitis. Light and electron microscopic findings. Gastroenterology 51: 825-840.

40. Donnellan WL (1966) Early histological changes in ulcerative colitis. A light and electron microscopic study. Gastroenterology 50: 519-540.

41. Nagle GJ, Kurtz SM (1967) Electron microscopy of the human rectal mucosa. A comparison of idiopathic ulcerative colitis with inflammation of known etiologies. Am J Dig Dis 12: 541-567.

42. O'Connor IJ (1972) An electron microscopic study of inflammatory colonic disease. Dis Colon Rectum 15: 265-277.

43. Campbell BJ, Finnie IA, Hounsell EF, Rhodes JM (1995) Direct demonstration of increased expression of Thomsen-Friedenreich (TF) antigen in colonic adenocarcinoma and ulcerative colitis mucin and its concealment in normal mucin. J Clin Invest 95: 571-576.

44. Mahida YR, Wu K, Jewell DP (1989) Enhanced production of interleukin 1beta by mononuclear cells isolated from mucosa with active ulcerative colitis of Crohn's disease. Gut 30: 835-838.

45. Gionchetti P, Campieri M, Belluzzi A, Tampieri M, Bertinelli E, et al. (1992) Interleukin 1 beta (IL-1 beta) release from fresh and cultured colonic mucosa in patients with ulcerative colitis (UC). Agents Actions Spec No: C50-52.

46. Olson AD, Ayass M, Chensue S (1993) Tumor necrosis factor and IL-1 beta expression in pediatric patients with inflammatory bowel disease. J Pediatr Gastroenterol Nutr 16: 241-246.

47. Fuss IJ, Neurath M, Boirivant M, Klein JS, de la Motte C, et al. (1996) Disparate CD4+ lamina propria (LP) lymphokine secretion profiles in inflammatory bowel disease. Crohn's disease LP cells manifest increased secretion of IFN-gamma, whereas ulcerative colitis LP cells manifest increased secretion of IL-5. J Immunol 157: 1261-1270.

48. Reimund JM, Wittersheim C, Dumont S, Muller CD, Baumann R, et al. (1996) Mucosal inflammatory cytokine production by intestinal biopsies in patients with ulcerative colitis and Crohn's disease. J Clin Immunol 16 $144-150$.

49. Vainer B, Nielsen OH, Hendel J, Horn T, Kirman I (2000) Colonic expression and synthesis of interleukin 13 and interleukin 15 in inflammatory bowel disease. Cytokine 12: 1531-1536.

50. Fuss IJ, Heller F, Boirivant M, Leon F, Yoshida M, et al. (2004) Nonclassical CD1d-restricted NK T cells that produce IL-13 characterize an atypical Th2 response in ulcerative colitis. J Clin Invest 113: 1490-1497.

51. Kadivar K, Ruchelli ED, Markowitz JE, Defelice ML, Strogatz ML, et al. (2004) Intestinal interleukin-13 in pediatric inflammatory bowel disease patients. Inflamm Bowel Dis 10: 593-598.

52. Heller F, Florian P, Bojarski C, Richter J, Christ M, et al. (2005) Interleukin13 is the key effector Th2 cytokine in ulcerative colitis that affects epithelial tight junctions, apoptosis, and cell restitution. Gastroenterology 129: $550-564$.

53. Heller F, Fuss IJ, Nieuwenhuis EE, Blumberg RS, Strober W (2002) Oxazolone colitis, a Th2 colitis model resembling ulcerative colitis, is mediated by IL-13-producing NK-T cells. Immunity 17: 629-638.

54. McDermott JR, Humphreys NE, Forman SP, Donaldson DD, Grencis RK
(2005) Intraepithelial NK cell-derived IL-13 induces intestinal pathology associated with nematode infection. J Immunol 175: 3207-3213.

55. Jenkins RT, Ramage JK, Jones DB, Collins SM, Goodacre RL, et al. (1988) Small bowel and colonic permeability to 51Cr-EDTA in patients with active inflammatory bowel disease. Clin Invest Med 11: 151-155.

56. Wang F, Graham WV, Wang Y, Witkowski ED, Schwarz BT, et al. (2005) Interferon-gamma and tumor necrosis factor-alpha synergize to induce intestinal epithelial barrier dysfunction by up-regulating myosin light chain kinase expression. Am J Pathol 166: 409-419.

57. Majors AK, Austin RC, de la Motte CA, Pyeritz RE, Hascall VC, et al. (2003) Endoplasmic reticulum stress induces hyaluronan deposition and leukocyte adhesion. J Biol Chem 278: 47223-47231.

58. Zhang K, Shen X, Wu J, Sakaki K, Saunders T, et al. (2006) Endoplasmic reticulum stress activates cleavage of CREBH to induce a systemic inflammatory response. Cell 124: 587-599.

59. Shkoda A, Ruiz P, Daniel H, Kim S, Rogler G, et al. (2007) Interleukin 10 blocked endoplasmic reticulum stress in intestinal epithelial cells: Impact on chronic inflammation. Gastroenterology 132: 190-207.

60. Pahl HL, Baeuerle PA (1995) A novel signal transduction pathway from the endoplasmic reticulum to the nucleus is mediated by transcription factor NF-kappa B. EMBO J 14: 2580-2588.

61. Rogler G, Brand K, Vogl D, Page S, Hofmeister R, et al. (1998) Nuclear factor kappaB is activated in macrophages and epithelial cells of inflamed intestinal mucosa. Gastroenterology 115: 357-369.

62. Andresen L, Jorgensen VL, Perner A, Hansen A, Eugen-Olsen J, et al. (2005) Activation of nuclear factor kappaB in colonic mucosa from patients with collagenous and ulcerative colitis. Gut 54: 503-509.

63. Bodger K, Halfvarson J, Dodson A, Campbell F, Wilson S, et al. (2006) Abnormal colonic glycoprotein expression in unaffected monozygotic twins of inflammatory bowel disease patients. Gut 55: 973-977.

64. Shroyer NF, Wallis D, Venken KJ, Bellen HJ, Zoghbi HY (2005) Gfi1 functions downstream of Math1 to control intestinal secretory cell subtype allocation and differentiation. Genes Dev 19: 2412-2417.

65. Longman RJ, Poulsom R, Corfield AP, Warren BF, Wright NA, et al. (2006) Alterations in the composition of the supramucosal defense barrier in relation to disease severity of ulcerative colitis. J Histochem Cytochem 54: 1335-1348.

66. Bertolotti A, Wang X, Novoa I, Jungreis R, Schlessinger K, et al. (2001) Increased sensitivity to dextran sodium sulfate colitis in IRE1beta-deficient mice. J Clin Invest 107: 585-593.

67. Dvorak AM, Dickersin GR (1980) Crohn's disease: transmission electron microscopic studies. I. Barrier function. Possible changes related to alterations of cell coat, mucous coat, epithelial cells, and Paneth cells. Hum Pathol 11: 561-571.

68. Meusser B, Hirsch C, Jarosch E, Sommer T (2005) ERAD: the long road to destruction. Nat Cell Biol 7: 766-772.

69. Michiels IJ, Berneman Z, Gadisseur A, van der Planken M, Schroyens W, et al. (2006) Classification and characterization of hereditary types 2A, 2B, 2C, 2D, 2E, 2M, 2N, and 2U (unclassifiable) von Willebrand disease. Clin Appl Thromb Hemost 12: 397-420.

70. Williams CN, Kocher K, Lander ES, Daly MJ, Rioux JD (2002) Using a genome-wide scan and meta-analysis to identify a novel IBD locus and confirm previously identified IBD loci. Inflamm Bowel Dis 8: 375-381.

71. Swallow DM, Vinall LE, Gum JR, Kim YS, Yang HY, et al. (1999) Ulcerative colitis is not associated with differences in MUC2 mucin allele length. J Med Genet 36: 859-860.

72. Moehle C, Ackermann N, Langmann T, Aslanidis C, Kel A, et al. (2006) Aberrant intestinal expression and allelic variants of mucin genes associated with inflammatory bowel disease. J Mol Med 84: 1055-1066.

73. Dixon AL, Liang L, Moffatt MF, Chen W, Heath S, et al. (2007) A genomewide association study of global gene expression. Nat Genet 39: 1202-1207.

74. Xue X, Piao JH, Nakajima A, Sakon-Komazawa S, Kojima Y, et al. (2005) Tumor necrosis factor alpha (TNFalpha) induces the unfolded protein response (UPR) in a reactive oxygen species (ROS)-dependent fashion, and the UPR counteracts ROS accumulation by TNFalpha. J Biol Chem 280; 33917-33925.

75. Hogan SP, Seidu L, Blanchard C, Groschwitz K, Mishra A, et al. (2006) Resistin-like molecule beta regulates innate colonic function: barrier integrity and inflammation susceptibility. J Allergy Clin Immunol 118: 257268.

76. McVay LD, Keilbaugh SA, Wong TM, Kierstein S, Shin ME, et al. (2006) Absence of bacterially induced RELMbeta reduces injury in the dextran sodium sulfate model of colitis. J Clin Invest 116: 2914-2923. 


\section{Editors' Summary}

Background. Inflammatory bowel diseases (IBD) are common disorders in which parts of the digestive tract become inflamed. The two main types of IBD are Crohn's disease, which mainly affects the small bowel, and ulcerative colitis (UC), which mainly affects the large bowel (colon). Both types tend to run in families and usually develop between 15 and 35 years old. Their symptoms include diarrhea, abdominal cramps, and unintentional weight loss. These symptoms can vary in severity, can be chronic (persistent) or intermittent, and may start gradually or suddenly. There is no cure for IBD (except removal of the affected part of the digestive tract), but drugs that modulate the immune system (for example, corticosteroids) or that inhibit "proinflammatory cytokines" (proteins made by the immune system that stimulate inflammation) can sometimes help.

Why Was This Study Done? Although the clinical and pathological (disease-associated) features of Crohn's disease and UC are somewhat different, both disorders are probably caused by an immune system imbalance. Normally, the immune system protects the body from potentially harmful microbes in the gut but does not react to the many harmless bacteria that live there or to the food that passes along the digestive tract. In IBD, the immune system becomes overactive for unknown reasons, and lymphocytes (immune system cells) accumulate in the lining of the bowel and cause inflammation. In this study, the researchers use a technique called random mutagenesis (the random introduction of small changes, called mutations, into the genes of an organism using a chemical that damages DNA) to develop two mouse models that resemble human UC and that throw new light on to how this disorder develops.

What Did the Researchers Do and Find? The researchers establish two mutant mouse strains-Winnie and Eeyore mice-that develop mild spontaneous inflammation of the colon and chronic diarrhea and that have more proinflammatory cytokines and more lymphocytes in their colons than normal mice. $25 \%$ and $40 \%$ of the Winnie and Eeyore mice, respectively, have severe clinical signs of colitis by 1 year of age. Both strains have a mutation in the Muc2 gene, which codes for MUC2 mucin the main protein in mucus. This viscous substance (which coats the inside of the intestine) is produced by and stored in intestinal "goblet" cells. Mucus helps to maintain the intestine's immunological balance but is depleted in UC. The researchers show that the manufacture and assembly of Muc2 molecules is abnormal in Winnie and Eeyore mice, that less mucin is stored in their goblet cells than in normal mice, and that their intestinal mucus barrier is reduced. In addition, an incompletely assembled version of the molecule, called Muc2 precursor, accumulates in the endoplasmic reticulum (ER; the cellular apparatus that prepares newly manufactured proteins for release) of goblet cells, leading to overload with abnormal protein and causing a state of cellular distress known as the "ER stress response." Finally, the researchers report that MUC2 precursor also accumulates in the goblet cells of people with UC and that even the noninflamed intestinal tissue of these patients shows signs of ER stress.

What Do These Findings Mean? These findings indicate that mucin abnormalities and ER stress can initiate colitis in mice. Results from animal studies do not always reflect what happens in people, but these findings, together with those from the small study in humans, suggest that ER stress-related mucin depletion could be a component in the development of human colitis. The results do not identify the genetic changes and/or environmental factors that might trigger ER stress in human colitis, but suggest that once initiated, ER stress might interfere with MUC2 production, which would lead to a diminished mucus barrier, expose the lining of the intestine to more toxins and foreign substances, and trigger local mucosal inflammation. The release of inflammatory cytokines would then damage the intestine's lining and exacerbate ER stress, thus setting up a cycle of intestinal damage and inflammation. Clinical studies to look for genetic changes and environmental factors capable of triggering ER stress and for ER-stress related changes in human UC should now be undertaken to test this hypothesis.

Additional Information. Please access these Web sites via the online version of this summary at http://dx.doi.org/10.1371/journal.pmed. 0050054.

- The MedlinePlus Encyclopedia has pages on Crohn's disease and on ulcerative colitis (in English and Spanish)

- The US National Institute of Diabetes and Digestive and Kidney Diseases provides information on Crohn's disease and ulcerative colitis

- Information and support for patients with inflammatory bowel disease and their caregivers is provided by the Crohn's and Colitis Foundation of America and by the UK National Association for Colitis and Crohn's Disease

- Wikipedia has pages on mucins and on mucus (note that Wikipedia is a free online encyclopedia that anyone can edit; available in several languages) 


\section{University Library}

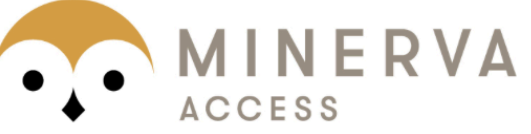

A gateway to Melbourne's research publications

Minerva Access is the Institutional Repository of The University of Melbourne

Author/s:

Heazlewood, CK;Cook, MC;Eri, R;Price, GR;Tauro, SB;Taupin, D;Thornton, DJ;Png,

CW;Crockford, TL;Cornall, RJ;Adams, R;Kato, M;Nelms, KA;Hong, NA;Florin, THJ;Goodnow, CC;McGuckin, MA

Title:

Aberrant mucin assembly in mice causes endoplasmic reticulum stress and spontaneous inflammation resembling ulcerative colitis

Date:

2008-03-01

Citation:

Heazlewood, C. K., Cook, M. C., Eri, R., Price, G. R., Tauro, S. B., Taupin, D., Thornton, D. J., Png, C. W., Crockford, T. L., Cornall, R. J., Adams, R., Kato, M., Nelms, K. A., Hong, N. A., Florin, T. H. J., Goodnow, C. C. \& McGuckin, M. A. (2008). Aberrant mucin assembly in mice causes endoplasmic reticulum stress and spontaneous inflammation resembling ulcerative colitis. PLOS MEDICINE, 5 (3), pp.440-460. https://doi.org/10.1371/journal.pmed.0050054.

Persistent Link:

http://hdl.handle.net/11343/255648

License:

CC BY 